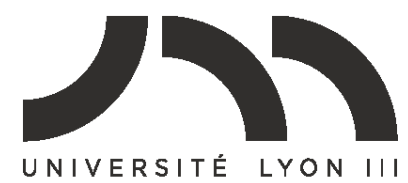

\title{
JEAN MOULIN
}

\section{Pauline Rodet}

\section{Verbal and Visual Metaphors Representing Brexit: Language Shaping Reality}

RODET Pauline. Verbal and Visual Metaphors Representing Brexit : Language Shaping Reality, sous la direction de Denis Jamet. - Lyon : Université Jean Moulin (Lyon 3), 2018.

Mémoire soutenu le 25/06/2018.

\section{(c) $(1) \Theta \Theta$}

Document diffusé sous le contrat Creative Commons «Paternité - pas d'utilisation commerciale - pas de modification » : vous êtes libre de le reproduire, de le distribuer et de le communiquer au public à condition d'en mentionner le nom de l'auteur et de ne pas le modifier, le transformer, l'adapter ni l'utiliser à des fins commerciales. 


\section{ר UNIVERSITÉ JEAN MOULIN LYON III FACULTÉ DES LANGUES}

Mémoire de Master 2

LLCER Recherche Etudes Anglophones

\section{Verbal and Visual Metaphors Representing Brexit: Language Shaping Reality}

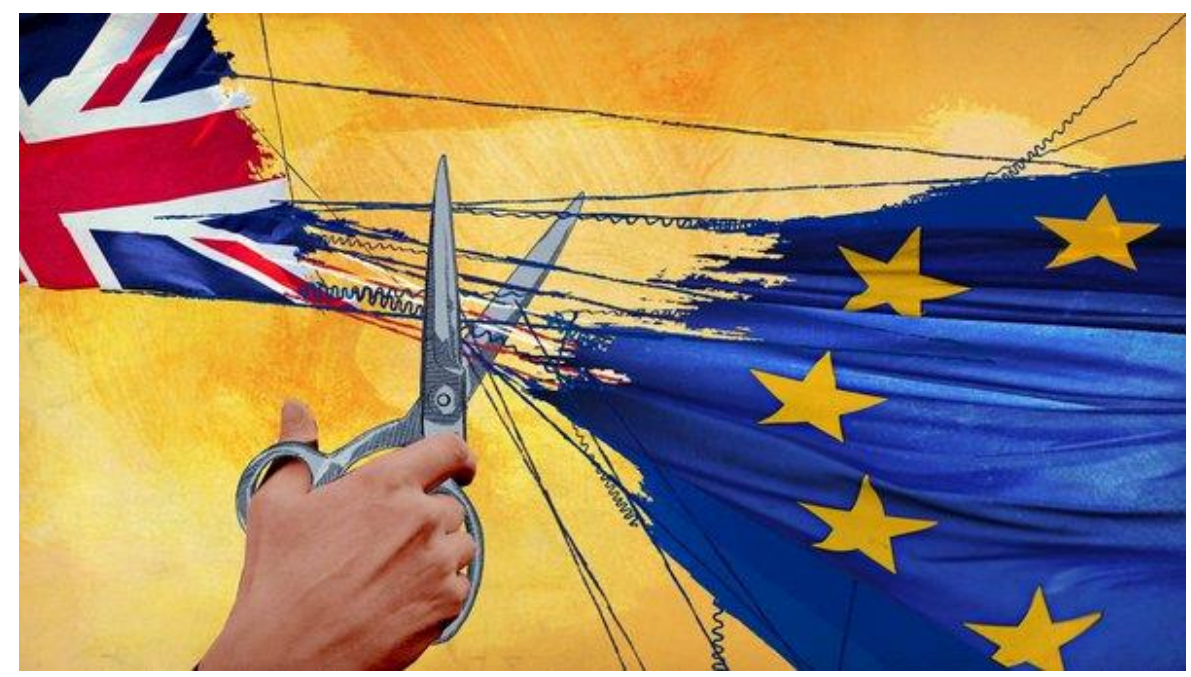

Par Pauline Rodet

Sous la direction de Monsieur le Professeur Denis Jamet

Année universitaire 2017-2018 



\section{Acknowledgments}

I would like to sincerely thank my supervisor, Denis Jamet, for his patience, guidance, and for arousing my interest in linguistics.

My special thanks go to Yoan Sechi and Oriane Hernandez, my trusty library partners, for their help and support.

I wish to acknowledge the help provided by Lucie Ratail, who kindly accepted to proofread my introduction and my bibliography.

Finally, I would also like to thank Adeline Terry for her helpful remarks during the Masteriales. 


\section{Table of Content}

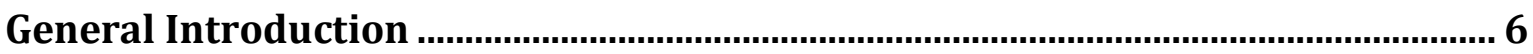

Part I: Theoretical Framework on Metaphors ......................................................11

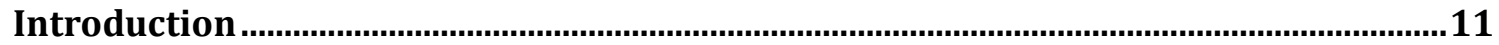

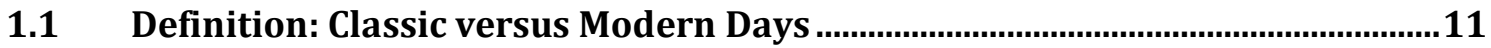

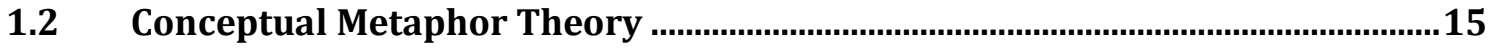

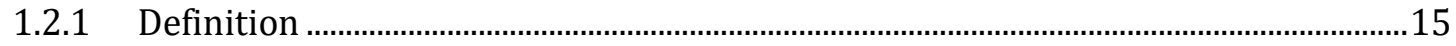

1.2.2 Metaphor Shaping our Thoughts..................................................................................18

1.2.3 Motivation: Metaphor and Our Experience of the World .............................................19

1.2.4 Hiding Highlighting Principle ………………..................................................................22

1.2.5 Conceptual Blending Theory .......................................................................................2

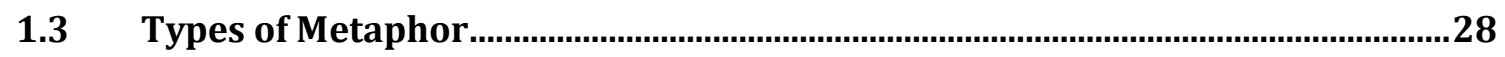

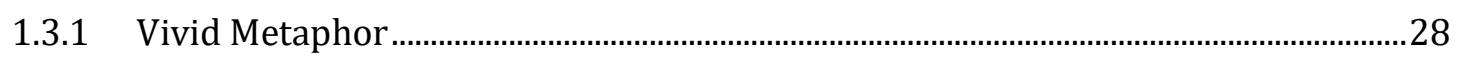

1.3.2 Semi-lexicalized Metaphor ..........................................................................................

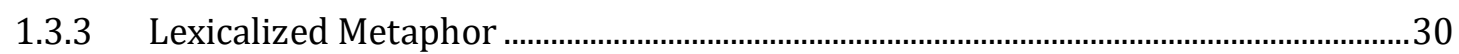

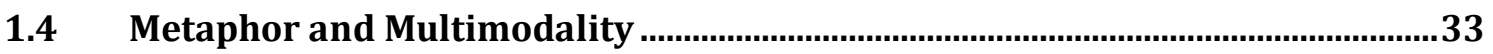

1.4.1 Monomodal Metaphor...................................................................................................

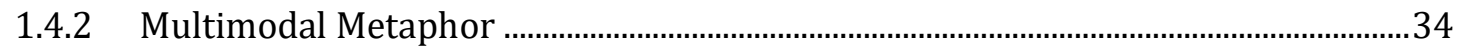

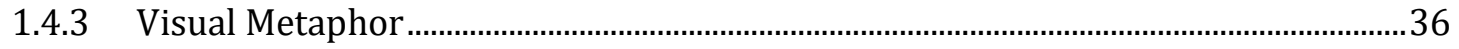

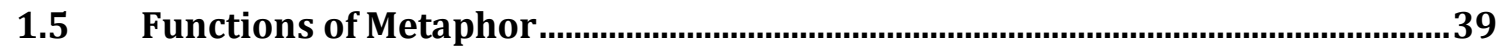

1.5.1 The Cognitive Function ...................................................................................................

1.5.2 The Ornamental Function............................................................................................40

1.5.3 The Didactic Function ...............................................................................................

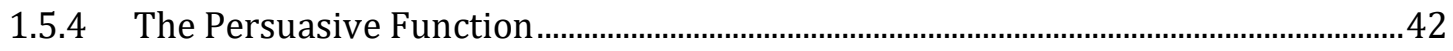

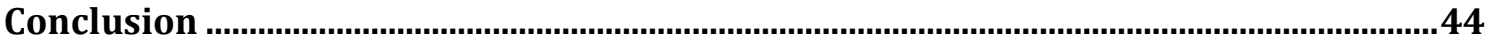

Part II: Metaphor and Political Discourse ...............................................................45

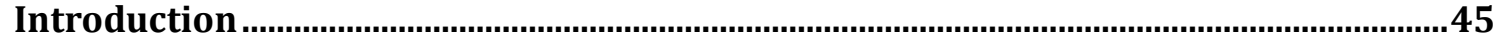

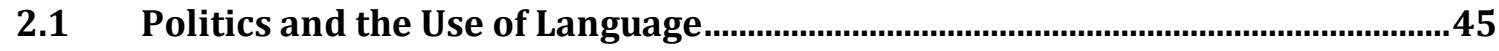

2.1.1 Persuasion and Rhetoric: Aristotelian View ..............................................................48

2.2 The Use of Metaphors in Political Discourse …........................................................51

2.2.1 Conceptual Metaphor Theory Applied to Politics...................................................51

2.2.2 Metaphor and Persuasion ....................................................................................... 52 
2.3 Analysing Metaphors in Discourse: Critical approaches …....................................56

2.3.1 Critical Discourse Analysis …………………….......................................................56

2.3.2 Critical Metaphor Analysis.......................................................................................58

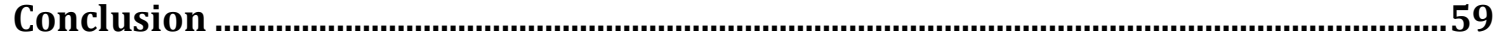

Part III: Case Study: Metaphors Shaping Brexit Discourse .....................................60

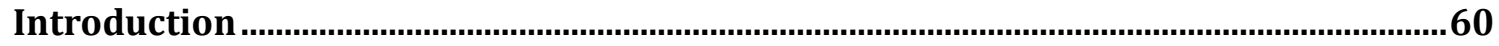

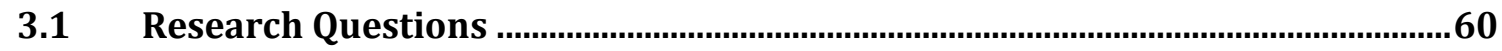

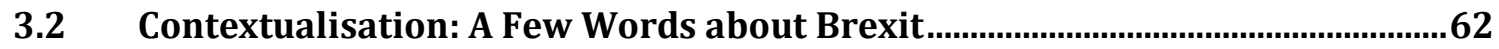

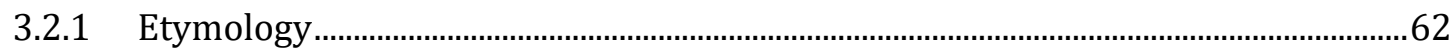

3.2.2 The EU Membership Referendum............................................................................63

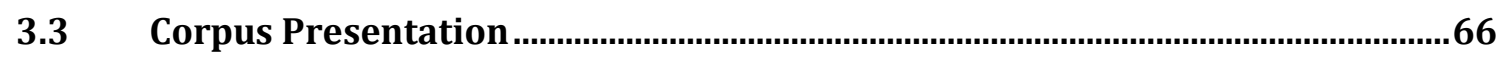

3.3.1 Verbal Data: Presentation and Methodology ..............................................................66

3.3.2 Visual Data: Presentation and Methodology ……………………………………….....69

3.4 Corpus Analysis: Visual Metaphors....................................................................... 70

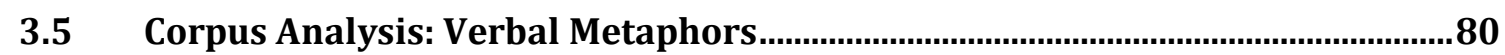

3.5.1 Written Documents ..........................................................................................................

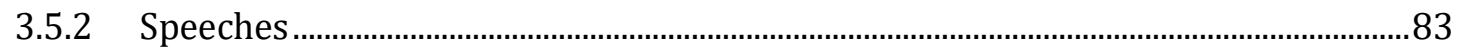

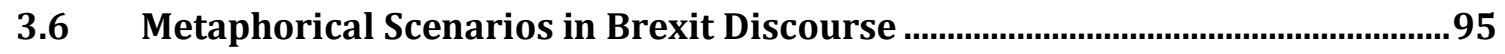

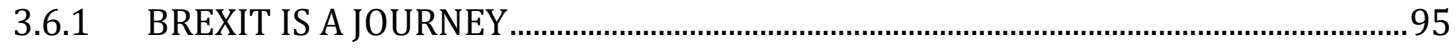

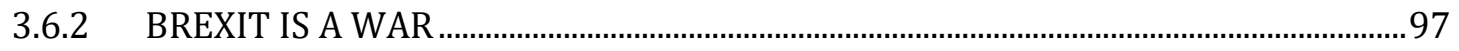

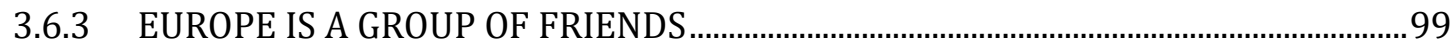

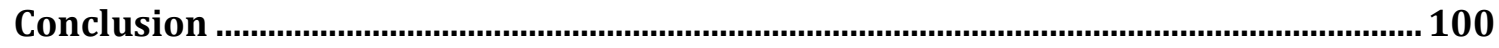

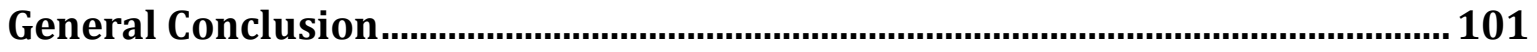

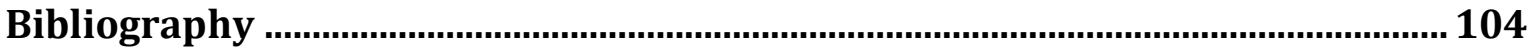




\section{General Introduction}

The year 2016 was a year of considerable disruption for the European political sphere. The political stability of the European Union was threatened by Britain's refusal to submit to European policies, which led to the unexpected and unprecedented event known as Brexit, that is, Britain's decision to withdraw from the European Union in the aftermath of a national referendum. From the early stages of the campaign prior to the referendum on the EU membership until now, politicians on all sides have been arguing on this much topical subject, fighting on whether Brexit was a suitable decision or not, and quarrelling over the future of the relationship between the European Union and the United Kingdom. Both in the European and British Parliament, as well as in the media, Brexit is a topic which has been written on and talked about extensively. Yet, Brexit being such an abstract and blurry event, many metaphors have been used to talk about it. As pointed out by journalist James Landale in a BBC article (2017): "Like the thin twig of peace, the Brexit metaphor has been stretched out to melting point. It should be taken round the back of the paragraph and quietly put out of its misery." It seems that people need to make sense of it by bringing it closer to what they already know, leading them to use metaphors comparing Brexit to a divorce, a broken friendship, or even a chocolate orange. In fact, from a cognitive stance, it is not really surprising to encounter that many metaphors around Brexit, since, according to George Lakoff and Mark Johnson, the two pioneers of the cognitive linguistics movement, metaphors are pervasive in everyday life and language. All the more so as they allow people to conceptualise abstract entities and events, as is the case for Brexit for instance. This is one of the most basic functions that metaphors can endorse 
according to them. However, metaphors can also often be used in contexts in which they are not necessarily needed. In that case, it seems that they can possibly be used in order to trigger some kind of added effect as they are scarcely picked up at random. This is even more relevant considering the context in which they appear. In the case of a political discourse, for instance, there is no shadow of a doubt that most metaphors are used deliberately to provoke some effect on the audience, or to convey the ideology of the utterer in a subversive manner. On that account, it is worth paying attention to the use of metaphors in the political domain. For this reason, this thesis will focus on metaphors in political discourse, and more specifically in discourse made in the context surrounding Brexit. I will try to answer the following questions: What verbal and visual metaphors are used to depict Brexit? What image or images do they convey? Do they vary according to various factors such as political stance or country? Were they similar before and after the referendum? To answer these questions, this study will be based upon a corpus constituted of elements of different types. Both visual and verbal elements will be studied. Concerning the analysis of verbal metaphors, I decided to analyse speeches and legal written documents such as political manifestoes, and the famous letter written by Theresa May that officialised Britain's exit from the European Union. The speeches were chosen so as to represent a variety of opinions on that matter. This corpus encompasses speeches made before and after the referendum, speeches from various political parties, and from various countries. In addition to that, this study will also take into account a couple of images representing Brexit metaphorically, which will allow us to have an insight into the multimodality of metaphors. Multimodality and metaphors are of particular interest since, as suggested by Lakoff and Johnson, if metaphors are, indeed, part of our conceptual 
system, they should indubitably appear in other modes than language alone. Language is not the only way human beings can express their thoughts. At least, this is the thesis developed by linguists such as Charles Forceville.

This study will be divided into three parts. The purpose of the first part will be to give a global overview of metaphors. Several definitions will be provided: starting from Aristotle's to nowadays' consideration of metaphors as conceptual devices. The framework of analysis this study comes under the scope of, that is, the Conceptual Metaphor Theory, will then be presented in details. I will go through the main principles of this theory, the link that metaphors maintain with one's thoughts, the principal motivations lying behind metaphors and the consequences that the use of metaphors triggers. Another note-worthy theory about metaphors will be dealt with, namely, the Conceptual Blending Theory, as it also links metaphors with our thought system. Furthermore, metaphors can be declined into several subcategories, or rather several types. These types of metaphors can be divided according to their level of lexicalisation, that is to say, how entrenched in language they are. Lexicalisation allows linguists to distinguish between three types of metaphors: vivid metaphors, semi-lexicalised and lexicalised metaphors. These three types of metaphors will, therefore, be defined and explained. While the first half of this part will mainly deal with linguistic metaphors, metaphors that are expressed through language, the second half will begin with Charles Forceville's theory on multimodal metaphors. This will invite the reader to go beyond the linguistic boundaries so as to see that metaphors are so pervasive in our life that they occur not only through language, but also through a variety of other modes that will be listed. What is more, metaphors can even be expressed via more than one mode, hence the appellation multimodal metaphors, which will also be explained in this part. To finish with, light 
will be shed on visual metaphors as it will be one of the main objects of study for this thesis. This first part will end with the different functions that metaphors can endorse, starting from the most obvious one, the cognitive function, and finishing with the subtlest but also the worthiest of interest for this study: the persuasive function.

The second part will aim to bridge the gap between metaphors and political discourse. To do so, I will start explaining the link between language and politics, and why language is so important to politics. This will lead the path to the following subpart which will deal with persuasion and rhetoric, including Aristotle's theory on that point. The next subpart will dig into the heart of the subject as it will address the question of the use of metaphors in political discourse. More specifically, it will try to link the Conceptual Metaphor Theory with the use of metaphors in political discourse. Most importantly, this part will also look into the persuasive function of metaphors in political discourse. The final subpart will present two models of analysis that are related to this study. First, the Critical Discourse Analysis will be presented as it is one of the most popular methods of discourse analysis, especially for linguists interested in political discourse and how political discourse can hide ideologies and promote inequalities. In short, this critical approach to discourse allows linguists to focus on the essence of a discourse, what lies behind the words, removing any form of embellishment. The other method of analysis presented in this part is the Critical Metaphor Analysis. This method provides a way to analyse metaphors in discourse. All in all, it provides the key to deciphering what metaphors really mean, which will set the path for the following part.

Last but not least, Part III will be devoted to my corpus and its analysis. To begin with, I will establish the research questions this analysis will try to answer. 
Then, the second subpart will introduce the context of the study from a historical point of view. Firstly, I will try to define what Brexit means from a lexical point of view. I will explain in which context this term first appeared, as well as its etymology. This will be followed by a brief historical account of the events that led to Brexit, starting from the events leading David Cameron to take the decision to propose a referendum on EU membership to the results of the referendum one year later and the current state of affairs. This step is essential for the understanding and interpretation of metaphors. The ensuing subpart will present the data I have worked with in full and complete details. I have divided my corpus into two categories. On the one hand, I will present the visual data and on the other hand, I will focus on the verbal data. The visual part of my corpus is constituted of five pictures from the web. The verbal data encompasses written documents, such as political manifestoes and one emblematic letter drafted by Prime Minister Theresa May, and six speeches that I deemed emblematic and worthy of interest. Alongside the presentation of the corpus, I will explain each stage that will guide my analysis, and that guided my choice concerning the selection of the elements constituting my corpus. Finally, I will move on to the analysis of the metaphors for each element of the corpus. The very last subpart will consist in an in-depth study of the most recurrent conceptual metaphors. 


\section{Part I: Theoretical Framework on Metaphors}

\section{Introduction}

So as to be able to carry out an analysis of metaphors in a corpus, and to be able to identify them, it is essential to get a proper sense of what they genuinely are, their more salient traits and how they work and what they truly induce. Thus, this first part will aim to establish the theoretical framework of the analysis. It will start by providing a diachronic overview of the definitions ascribed to this linguistic and mental process before jumping onto cognitive theories, which will be our main angle of approach for the corpus analysis that will follow. In addition, three different types of metaphors will be detailed, and some of the most relevant functions that metaphors can endorse will be explained. Finally, the issue of multimodality will be raised for metaphor is not essentially a matter of language.

\subsection{Definition: Classic versus Modern Days}

Defining metaphors involves us to take a step back, make a little jump across time and go back to the original definition of this process before coming back to more modern theories. Metaphors have been an object of study ever since Ancient Greek philosophers started to wonder about how language works. Initially, metaphors were mostly studied for their rhetorical purpose. One of the first definitions of metaphor that was ever given can be traced back to Aristotle and his eminent works Rhetoric and Poetics. His theory consisted in assuming that metaphors were a way to "give a thing a name that belongs to something else; the transference being either from genus to species, or from species to genus, or from 
species to species, or on grounds of analogy" (107: 1457b). Although it may have sounded quite revolutionary at that time, Aristotle's definition seems slightly outdated nowadays since it is now possible to distinguish between several types of "transfers of meaning", as they do not all fall under the appellation of metaphor. As rightly pointed out by Paul Ricoeur in The Rule of Metaphor, the word metaphor for Aristotle described all transpositions of terms (1975: 24). He did not make any distinction between simile, metonymy, synecdoche and metaphor, which, as we know now, do not really work in the same way although they are all figures of speech, meaning that they all belong to the realm of non-literal language and used as rhetorical devices which rely upon the principle of comparison. That is to say, when using a metaphor, whether deliberately or not, a comparison is often made between the entity one is literally referring to and the entity one is using metaphorically to refer to the other thing. However, this notion of figure of speech needs to be taken cautiously as now; we tend to consider that there is more to metaphors than simply figures of speech. More recent theories brought about by cognitive linguists will actually aim to deconstruct this false assumption.

Furthermore, the etymology of the word metaphor tells us a lot about its meaning and corroborates Aristotle's point of view. According to the website etymonline.com, the term metaphor comes from the Greek metaphora which literally means transfer, carrying over. This idea of transfer of meaning will prove to be an important characteristic of this process.

Another simple but rather broad definition that characterises metaphors would be the one provided by Knowles and Moon in their book Introducing Metaphor. They wrote that metaphors consist in referring to "something other than what it was originally applied to, or what it 'literally means' in order to suggest some 
resemblance or make a connection between two things" (2006: 3). It is true that the process of metaphorization relies upon the perception of similarity between two domains (Ricoeur 1975: 34). Using a metaphor to describe something or someone results in making an implicit comparison, that is a comparison without using comparative tools, and it highlights some kind of similarity between two entities. At least, this is one way of apprehending metaphors; we will see later on that it may differ for other schools of thoughts. Nonetheless, the similarity between the two domains at stake in a metaphor is only partial. Not all the elements of the one domain are transferred onto the second domain. As stated by Andrew Goatly (1997: 17): "an entity referred to metaphorically lacks at least one critical feature possessed by the conventional referent of the word." For instance, if we consider the following example: "This man is a pig." It is highly unlikely that the subject of this sentence literally refers to the actual animal. A person cannot literally be a pig. This metaphor suggests that the utterer perceives some common characteristics between the man in question and a pig. But not all characteristics of the domain of pig are transferred onto the domain of man. Accordingly, we are invited to take this sentence figuratively.

Knowles and Moon's definition also suggests that speaking metaphorically implies that we enter into the realm of figurative language rather than literal language, which is true since when a word is used metaphorically, most of the time the literal meaning of the utterance will not mean anything. But yet again, it can be argued that this definition provided by Knowles and Moon is slightly too broad and is not specific to metaphors alone.

Furthermore, one can acquire a better taste of how metaphor truly operates by looking at I. A. Richard's explanation given in his book The Philosophy of Rhetoric. 
He gave a more precise account of what "the two things" mentioned by Knowles and Moon were. He explained that metaphors are constituted of two distinguishable elements that he labelled the tenor and the vehicle. The tenor corresponds to the concept or person that is being talked about and the vehicle refers to the concept or person that is used to talk about the tenor (1981: 49). For instance, if we take a look at Carson McCullers' book entitled The Heart is a Lonely Hunter which is obviously metaphorical, the heart would be the tenor and the hunter would be the vehicle. By shedding light upon this dichotomy, I. A. Richard laid the foundations of the cognitive linguistic approach.

In brief, metaphor is an interesting phenomenon to study since, as mentioned by Max Black, when taken literally, metaphors don't mean anything and sometimes, they even assert something which is not (1993: 21), and they often don't make sense in the context in which they are uttered (Glucksberg 2008: 67). However, a metaphor not only is a use of language, it can also be seen as a way to think. That is what more recent linguists expressed by putting forward the Conceptual Metaphor Theory. 


\subsection{Conceptual Metaphor Theory}

The cognitive theory on metaphors will be the basis of this analysis, and more precisely the theory of the conceptual metaphor since metaphors are not only a rhetorical figure, but also participate in the way one perceives the world that surrounds them.

\subsubsection{Definition}

The Conceptual Metaphor Theory was first introduced by Lakoff and Johnson in their much acclaimed 1980's book Metaphors We Live By. They are now regarded as the fathers of cognitive linguistics. This is the path I intend to pursue in the corpus analysis that will follow. This theory was born from the assumption that metaphor is not a matter of language alone, but it is also pervasive in thoughts and action (Lakoff and Johnson 1980: 3). The main argument raised by Lakoff and Johnson is that "our conceptual system is largely metaphorical, the way we think, what we experience, and what we do every day is very much a matter of metaphor" (1980: 3). Metaphors are not solely rhetorical or linguistic phenomena, but are also present in our mind and are involved in the way we perceive the world that surrounds us. This approach was innovative in the sense that it does not only focus on the way we talk but also on the way we think.

The Conceptual Metaphor Theory presents metaphor as a mapping between two domains: a source domain and a target domain. In his practical introduction to metaphors, Kövecses gave a precise account of the difference between these two domains. According to him, the source domain corresponds to the domain from which metaphorical expressions are built, whereas the target domain corresponds 
to the domain that is being understood through the use of the source domain $(2002$ : 4). A source domain can be used for more than one target domain and the target domain can be talked about in terms of more than one source domain, as it is the case for the domain of LOVE for instance, which has more than twenty source domains attached to it such as JOURNEY, WAR and GAME (Kövecses, 2006: 120).

The act of using words from the source domain to talk about the target domain triggers a mapping, a transfer of meaning between the two domains as mentioned by Lakoff and Johnson. For instance, people tend to talk about the act of having an argument with expressions usually ascribed to the domain of war. This can be illustrated by various metaphorical expressions such as attack someone's argument, win an argument, defend a claim. The Conceptual Metaphor Theory can be illustrated as follows:

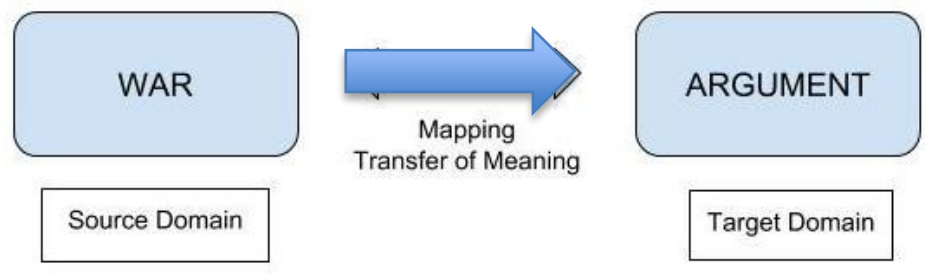

Figure 1: Schema Representing the Conceptual Metaphor ARGUMENT IS WAR.

In fact, not only do we talk about argument in terms of war, but we conceptualise the fact of having an argument through the source domain of war; this is how we understand it. We would not be able to talk about it in a different way otherwise it would not make any sense and it would not be as easily understood (Lakoff and Johnson 1980: 5). This is one of the most crucial points raised by the 
Conceptual Metaphor Theory. This shows that metaphor is not only a matter of language, but also a matter of thought and connections made at the level of the mind, hence the link to cognition.

Lakoff and Johnson's sets of criteria for identifying metaphors are the following: firstly, there must be a difference in the kind of activity and a partial structuring between the two concepts (1980: 85). If we then consider the conceptual metaphor ARGUMENT IS WAR mentioned above, we can see that it is, indeed a metaphor since argument is a different type of activity as it involves talking instead of physical fight. The structuring is also only partial since only selected items of the concept of WAR are used to conceptualise the act of having an argument: opposition, confrontation, attacking and defending (1980: 85).

However, it is important to bear in mind that not all the characteristics from the source domain are mapped onto the target domain (Gibbs and Steen 1999: 37). As said earlier, metaphor is based upon similarity; only the shared characteristics of both domains that allow people to perceive this similarity are mapped. It is also interesting to take into account that some other linguists such as Joseph Grady questioned this idea of similarity at the heart of metaphors (1999: 88). In a paper published in the collection Metaphor in Cognitive Linguistics, he argued that for some Conceptual Metaphors, the source and the target domains actually have nothing in common. This happens to be true if we look at the examples he gave. According to him, the Conceptual Metaphor HAPPY IS UP and expressions such as she is in high spirit are not based upon similarity as the source and the target domain do not seem to have any characteristic in common, the link between verticality and happiness is hardly visible. In fact, this illustrates the fact that metaphors are not always based 
on similarity. There are other elements to be taken into account for the motivation behind metaphors, a point that will be developed in a further section.

In addition, conceptual metaphors need not to be confused with metaphorical expressions. Metaphorical expressions are the linguistic representations of a conceptual metaphor which are commonly expressed in the form A IS B, A being the target domain and B being the source domain (Kövecses 2002: 29). However, it is important to remember that conceptual metaphors can be expressed through other forms than just through language alone. This will be developed later on when the topic of multimodal metaphors will be brought up.

\subsubsection{Metaphor Shaping our Thoughts}

As mentioned in the definition of the Conceptual Metaphor Theory, cognitive linguists highlighted the fact that metaphor shapes our thoughts about certain concepts (Lakoff and Johnson 1980: 4). Some entities, mostly abstract entities such as money, time and love, can only be thought of and talked about metaphorically. Accordingly, conceptual metaphors shape our thoughts about these abstract entities. Lakoff and Johnson's theses rely on the assumption that our conceptual system that allows us to think and act is the same that the one we use to talk, so we can assume that the way we talk reflects the way we think (Lakoff and Johnson 1980: 4). As a consequence, if we speak metaphorically, we can deduce that we think metaphorically too.

In order to show that metaphors indeed shape our thought, let us take a look at Paul Thibodeau and Lera Boroditsky's analysis on the role of metaphor in reasoning (2011). They carried out an experiment which shows how metaphors 
influence the way we reason about complex issues. They presented people with articles about crime; some of the articles contained metaphorical expressions comparing crime to a virus, and others comparing crime to a beast. Then, people were asked to propose ways to reduce the criminal rate. The results of the experiment revealed that metaphors systematically influenced how people talk about crime after reading the articles they were handed out. Participants who read that crime was a virus were more likely to propose solving crime issues by treating the core of the problem, just like a virus. On the contrary, people who read that crime was a beast were more likely to suggest fighting back against the crime, building jails, catching and caging criminals (2011: 5). They continued thinking and speaking within the same metaphorical frame they were exposed to. Thibodeau and Boroditsky concluded that "metaphors exert an influence over people's reasoning by instantiating frame-consistent knowledge structures" (2011: 9) and consequently, metaphors influence people's opinion and reasoning about real-world events. This can be linked to Kövecses's idea that metaphor exists in language only because it exists in the brain. Metaphor is primarily a matter of thoughts before becoming a linguistic phenomenon derivatively (2006: 122). Consequently, by shaping our thoughts, metaphor also shapes our language and our actions.

\subsubsection{Motivation: Metaphor and Our Experience of the World}

One may wonder about the way conceptual metaphors are built, about the underlying reasons that allow one to conceptualise one entity through a particular domain. As previously mentioned, similarity is not the only motive behind 
metaphors. So why is life conceptualised in terms of a journey, or argument in terms of war? The truth is, there is no straight answer to that, but rather a set of hypotheses which will be there developed.

Firstly, some conceptual metaphors can be explained by the fact that their source and target domains are somehow correlated in the extralinguistic world. In his introduction to metaphor, Kövecses illustrated this theory by giving the example of the conceptual metaphors MORE IS UP and LESS IS DOWN. Both these metaphors exist because there seems to be a correlation between the concepts of verticality and quantity in the extralinguistic world, and we can physically experience it (2002: 70). This can be shown by a simple and familiar experience. If we take an empty glass and fill it with water, we can notice that the more quantity we add to the glass, the more the level of the water rises and vice versa. So according to this experience, we can deduce that quantity and verticality are indeed linked, and that is why our conceptual system associates these concepts. This is all due to the fact that our spatial concept of UP comes from our spatial experience, our experience with our physical environment (Lakoff and Johnson 1980: 57). As stated by Lakoff: "these correspondences in real experience form the basis for the correspondences in metaphorical cases" (1993: 240).

Other metaphors may find their motivation in the way the human body functions (Kövecses 2002: 71). The conceptual metaphor ANGER IS HEAT would be a good example to illustrate this point of view. As can be noticed, when someone is angry, they may experience a feeling a heat taking over their body, as if their blood was boiling up. One can also experience redness in the face which could be comparable to being sunburnt. All in all, the way our body experience the feeling of 
anger determines the way we conceptualise it and, as a consequence, the way we talk about it.

Moreover, some metaphors can be based upon perceived similarity: similarity that can be objectively seen or that comes from the imagination of the utterer. For example, in Romeo and Juliet by Shakespeare, when Romeo says to Juliet you are my sun, it means that he probably perceives some kind of similarity between Juliet and the sun, but it is not obvious at first sight, it probably comes from his own imagination. The similarity may come from the way Juliet makes him feel for instance.

Furthermore, if we consider the example of the word mouse when it is used to refer to the object to scroll on a computer, it can be considered as a metaphorical use of the word mouse as it is based upon perceived similarity between the object and the animal: it can be argued that the computer-mouse looks like the animal in some way; they share physical common features like the shape and size of the body and the long wire attached to it that looks like a tail. However, some may argue that it is rather a case of catachresis than a case of metaphor since there is no other possibility to refer to it. But in fact, it is presumably a mix of the two. In sum, according to cognitive linguists, conceptual metaphors are based upon objective similarity, as it is the case with the example of the mouse, but also on a great number of human experiences (Kövecses 2002: 69).

The motivation hidden behind metaphor can be summed up in a quote from Lakoff: "these mappings are not arbitrary but grounded in the body and everyday experience and knowledge" (1993: 245). Lakoff and Johnson showed that "we typically conceptualize the nonphysical in terms of the physical" (1980: 60). 


\subsubsection{Hiding Highlighting Principle}

The principle of hiding-highlighting was put forward by Lakoff and Johnson in Metaphors We Live By. It ensues from the Conceptual Metaphor Theory. When using a metaphor to talk about a concept, person or object, we are implicitly shedding light upon what the source and the target domains have in common, their shared characteristics that enable us to build the metaphor. Yet, as quoted by novelist Murakami: "Where there is light, there must be shadow, where there is shadow there must be light." Thus, highlighting necessarily involves that what is not highlighted is in the shadow, is hidden. That is, as explained by Kövecses, when a concept used to build a metaphor is formed by several aspects, the metaphor will highlight the aspects that are common to the source and the target domain and will thus hide the aspects of the concept that are not shared by the two domains (2002: 88). If we use the same example of the conceptual metaphor ARGUMENT IS WAR, we can see that by using the domain of war to talk about the act of having an argument with someone, the competitive aspect of an argument is highlighted whereas the collaborative aspect of it is hidden because the concept of war particularly focuses on the competitive aspect, that is why this conceptual metaphor takes such a tint. This leads us to suggest that, in some context, the connotation that one wishes to express about something or someone can vary depending on which source domain we decide to associate it with.

Along these lines, it is possible to say that the hiding-highlighting principle can be peculiarly interesting to take into account in a study of metaphor in discourse, especially in political discourse, since depending on the choice of the source domain; a speaker will be able to convey their ideology and their reality in a 
certain way. They are able to highlight the parts of their discourse that suit them best and hide what they don't want people to focuse on. In a nutshell, it seems that metaphor tends to hide some features of the phenomena we connect them to and highlights others (Goatly 1997: 2). In short, the Conceptual Metaphor Theory revolutionised the way we apprehended metaphors for many centuries. It is an interesting framework to use for a corpus analysis since it gives us the opportunity to go beyond language and analyse how people think about certain issues and how people want others to think about certain issues thanks to the principle of hiding highlighting.

\subsubsection{Conceptual Blending Theory}

This theory is another way to look at metaphors from a cognitive point of view, albeit it is not solely confined to metaphors as it can also be applied to other devices such as analogies or metonymies. It is often opposed to the Conceptual Metaphor Theory. However, both these theories have much in common. As pointed out by Grady: "both approaches treat metaphor as a conceptual rather than a purely linguistic phenomenon" (1999: 101). Indeed, they both take into account the mental processes involved in metaphors. However, he noted two major differences between the Conceptual Metaphor Theory and the Blending Theory. According to him, "the Conceptual Metaphor Theory posits relationships between pairs of mental representations while the Blending Theory allows for more than two; Conceptual Metaphor Theory has defined metaphor as a strictly directional phenomenon, while BT has not." (1999: 101). In other words, in the Conceptual Metaphor Theory, metaphors are decomposed into two domains while in the Blending Theory, there can be more 
than two input spaces. Additionally, the mapping resulting from Conceptual Metaphor Theory follows a specific direction: the target domain is mapped onto the source domain, the mapping is unidirectional. While in the Blending Theory, the input spaces are mapped into each other, hence the two plain lines that bind the two circles in the diagram hereunder.

The Conceptual Blending Theory was developed by Gilles Fauconnier and Mark Turner in their book The Way We Think: Conceptual Blending and the Mind's Hidden Complexities published in 2002. This theory considers metaphors as conceptual projections that involve four different mental spaces (Hart 2007: 7). According to Fauconnier and Turner, mental spaces are "small conceptual packets constructed as we think and talk, for purpose of local understanding and action. They are interconnected, and can be modified as thought and discourse unfold" (1998: 13). Mental spaces correspond to mental associations that our brain constructs when talking and hearing someone talk. They are created in order to help us understand what is seen, and what is heard. Conceptual Blending usually involves four mental spaces: two input spaces, one generic space and one blended space. They are all represented in the following diagram: 


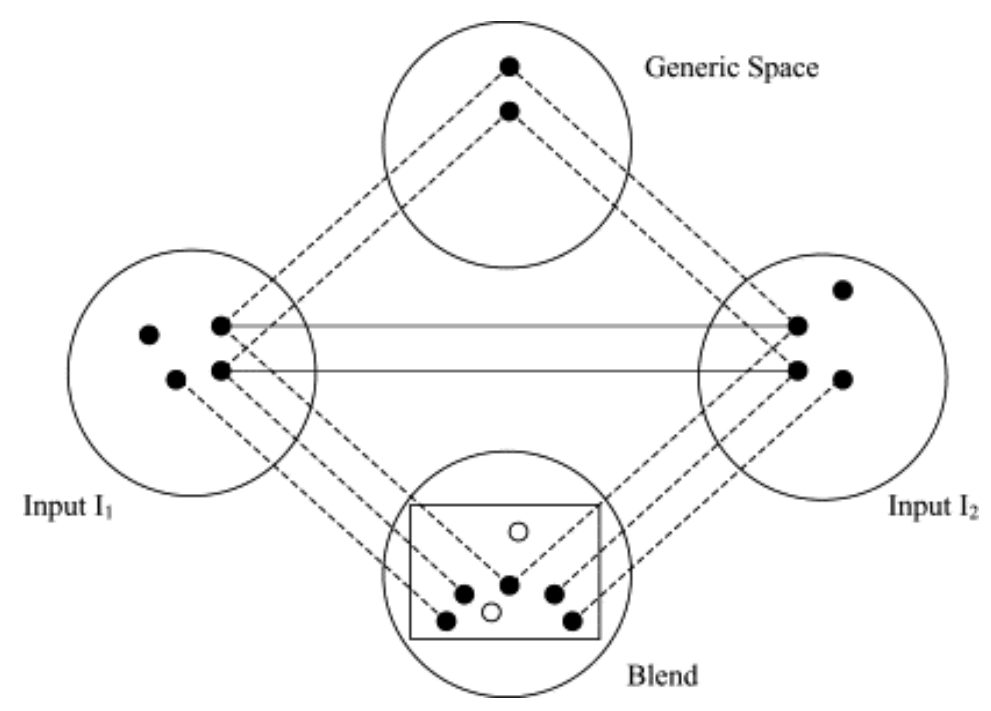

Figure 2: Diagram of a conceptual blending

First of all, the two input spaces correspond to the two concepts that are at the essence of the metaphor, that is, the two entities that are talked about. If we were to compare it to the Conceptual Metaphor Theory, we could say that inputs I1 and 12 correspond to the source and target domains. Nonetheless, domains in the Conceptual Metaphor Theory designate broad and general concepts, whereas in the Blending Theory, the input spaces correspond to a specific instantiation of a broad concept (Forceville 2010). The circle labelled generic space in the diagram contains abstract structures that are common to both input I1 and input I2. The generic space is the place where the shared characteristics of the two input spaces are bound together. Finally, the blended space at the bottom of the diagram is the result of the conceptual blending. Fauconnier and Turner described it as follows: "In blending, structure from two input spaces is projected to a separate space, 'the blend'. The blend inherits partial structure from the input spaces, and has emergent structure of its own" (1996: 113). The blend is the place where the two inputs are connected, and the emergent structure mentioned by Fauconnier and Turner corresponds to 
the mental space that is created as a result of the blending. The dots within the circles represent the elements within the mental spaces (Hart 2007: 109). The several lines that connect the four circles are the representation of the conceptual projections and neural coactivations (Fauconnier and Turner 2002: 46). To illustrate this theory, let us look at the example provided by Christopher Hart in his article dealing with the Blending Theory in political discourse. He used the example of Tony Blair comparing immigrants as "a flood of asylum seekers" in one of his speeches. Following the Blending Theory, flood and migration would be the two input spaces. The emergent structure resulting from the blend would be the fact that migration of people is conceptualised as a flood of water (Hart 2007: 113). As for the generic space, it contains the fact that a flood is an event and migration is a process, and events and processes are closely related. Thus, the generic space encompasses the relationship that unites these two processes (ibidem.). As a result of conceptual operations, the two input spaces are projected onto the fourth mental space: the blended space as shown in the schema hereunder. It shows that when hearing "a flood of asylum seekers", the brain connects the event of flood to the process of migration. 


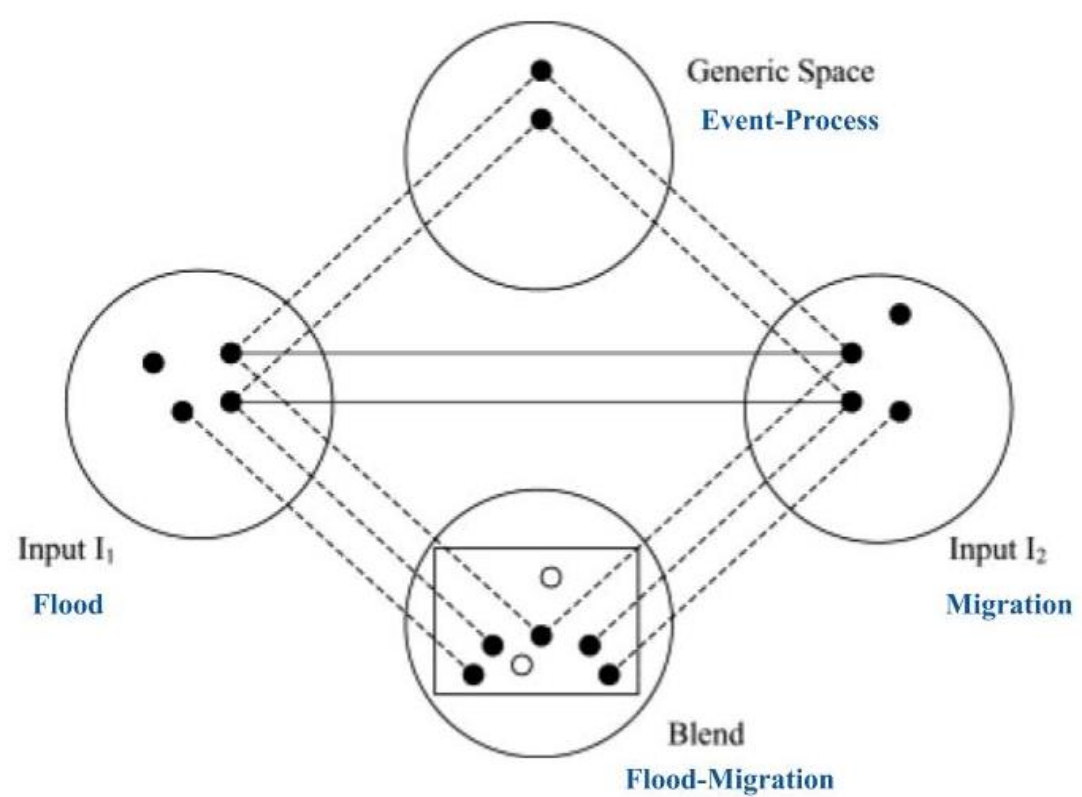

Figure 3: Conceptual Blending for "flood of asylum seekers" (Hart 2007: 113)

This shows that this theory too suggests a link between the way we talk, what we are told and how we think. When two entities are mentioned together in a metaphorical utterance, our brain associates them and highlights the elements they have in common. Along with the Conceptual Metaphor Theory, the Blending Theory offers a structure that helps us understand and reason about abstract entities (Grady et al. 1997: 121). In other words, cognitive theories show that metaphors are omnipresent in our thoughts, and they help us addi some clarity to obscurity. 


\subsection{Types of Metaphor}

Metaphor can be subdivided into several categories. There is not just one type of metaphors. They can be classified according to several factors. Here, I chose to classify them according to their level of lexicalisation. I decided to divide them into three sub-categories that could be placed on a continuum from the more atypical to the more conventional.

\subsubsection{Vivid Metaphor}

The least conventional type of metaphors is the one that is called vivid metaphor or novel metaphor. They are frequently encountered in literature, especially in poems but not only; they can also be found in other contexts such as speeches, for example. They are highly context-dependent and they are unlikely to be encountered more than once. A writer or speaker can use them in order to express a particular idea or feeling in a special context (Knowles and Moon 2006: 5). This type of metaphor generally gives colour to a text. Vivid metaphors catch the attention of the hearer or reader since they need more effort to be decoded as opposed to lexicalised metaphor; they need to be mentally reconstructed. An example to illustrate this type of metaphor in a literary context would be Walt Whitman's famous poem 0 Captain! My Captain! ${ }^{1}$ in which he used an extended metaphor ${ }^{2}$ to talk about Lincoln's assassination without ever mentioning his name.

\footnotetext{
$1_{1}$ Poem published in the collection Leaves of Grass, published in 1855.

${ }_{2}^{2}$ An extended metaphor is "a metaphor introduced and then further developed throughout all or part of a literary work" (Dictionnary.com)
} 
He wrote:

Here Captain! dear father!

This arm beneath your head!

It is some dream that on the deck,

You've fallen cold and dead.

Whitman used the figure of the Captain to refer metaphorically to Abraham Lincoln. It is, then, up to the reader to read through the lines and reconstruct the metaphor in order to grasp the full meaning of this poem. This also illustrates the fact that metaphors are often bound to culture and common shared knowledge. Someone who has no knowledge of American history would probably not be able to understand the metaphorical reference that lies within these verses.

In the same spirit, David Cameron's last farewell speech as Prime Minister of the United Kingdom also bears a good few examples of vivid metaphors. Here are examples of metaphorical expressions that he used:

"I will try to be the captain that steers our country to its next destination." "I will do everything I can to steady the ship over the coming weeks." (Cameron 2016)

It can be noticed that he compared himself to a captain steering a ship and the ship being a metaphor to talk about the United Kingdom. This example shows that contrary to popular belief, vivid metaphor, and more generally metaphor as a whole, is not strictly limited to literature but is present in many more domains. 


\subsubsection{Semi-lexicalized Metaphor}

This type of metaphor corresponds to the metaphors that are in between vivid and lexicalized metaphors. This type of metaphors is easily identifiable but not enough worn out so as to enter the dictionary. They are used a lot, but their imagistic dimension has not completely faded yet. Besides, studies have shown that idioms are not completely dead metaphors/lexicalized metaphors as one may think but rather semi-lexicalized since their degree of metaphoricity is still present to some extent (Gibbs 1999: 148). According to Gibbs, this could be due to the fact that "they arise from metaphorical mappings between dissimilar source and target domains (1999: 148). It is also much easier to understand them in context. Another element showing that this argument might be true is the fact that, for a foreigner learning English, it would probably be difficult to understand the meaning of an idiom such as kick the bucket or hit the ceiling if they don't read them in context or if they are not given an equivalent expression in their mother language, although they would be perfectly understood by a native English speaker because they are so used to seeing and hearing them. In sum, idioms are good examples of semi-lexicalized metaphor in the sense that they illustrate the ambiguous nature of semi-lexicalized metaphor.

\subsubsection{Lexicalized Metaphor}

Some metaphors are so commonly used that they are barely noticeable as we speak or read. As stated by Elena Semino in her book Metaphor in Discourse: "the more conventional a metaphorical expression, the less likely it is that it will be consciously used and recognized as metaphor" (2008: 19). They are utterly 
entrenched in language, so much that people do not notice them anymore. An easy way to recognize a lexicalized metaphor is to check into dictionaries, since it is generally admitted that a phrase or lexeme is considered as lexicalized as soon as it can be found in dictionaries. Andrew Goatly stated that "dictionaries are the cemeteries and the mortuaries and generally the resting place for the population of metaphors" (1997: 31), which is quite a relevant metaphor to understand this type of metaphors. Cornelia Muller argued that in the case of a lexicalized metaphor, which she refers to as dead metaphor, the imagistic or source dimension fades away and only the figurative meaning remains activated (2008: 4). In other words, in the case of dead or lexicalised metaphor, the source domain refers only to the abstract and derived meaning which is henceforth considered as the literal meaning (Gentner and Bowdle 2008: 118). For instance, if we refer to a film as a blockbuster as in: Harry Potter is a blockbuster, this can be considered as a case of lexicalized metaphor since we do not actively think about the literal meaning of blockbuster when hearing or reading this; the primary literal meaning of this word being "a very large high-explosive bomb" according to the Merriam-Webster dictionary.

Knowles and Moon argued that "metaphor is a basic process in the formation of words" (2006: 4). It is true that many new concepts are named metaphorically, especially when thinking about words that are related to the domains of technology and computer science such as bug, cookies, and window. Yet, the meaning of these words is so lexicalised that we do not perceive them as metaphors anymore, and we probably never did. They simply acquire a second meaning which is perfectly well entrenched in language. They became polysemous words. Gentner and Bowdle argued that metaphor was a primary source of polysemy (2008: 119). The first meaning would be the oldest one, or what Knowles and Moon call the core meaning 
(2006: 16) and the second meaning would be the one that had been acquired through a metaphorical process. This is interesting so far as it contradicts what Paul Ricoeur wrote in The Rule of Metaphor. To him, it is necessary to have at a least sentence to generate a metaphor (1975: vi). Yet, here we demonstrated that a metaphor can perfectly be generated through one simple word as it is the case with bug, cookies and window mentioned above. This leads to the assumption that metaphors are, indeed, pervasive in language. Besides, it also shows to what extent metaphors play such an crucial role in language (Knowles and Moon 2006: 4). 


\subsection{Metaphor and Multimodality}

So far, I have only been focusing on metaphors expressed linguistically, on what is called metaphorical expressions. Nevertheless, language is not the only way conceptual metaphors can be encountered; they can take various forms. Some linguists, including Charles Forceville and Eduardo Urios-Aparisi showed that, "metaphor is not primarily a matter of language" (2009: 4). In the book they edited dealing with multimodal metaphors, they pointed to the fact that if the Conceptual Metaphor Theory is veracious and that people genuinely think metaphorically, or if, as stated by Lakoff, "metaphor is not a figure of speech but a mode of thought" (Lakoff 1993: 210), it means that metaphor can occur in other semiotic modes than language alone (2009: 4). In his introduction to metaphor, Kövecses also agreed with this hypothesis as he wrote: "if metaphors are primarily conceptual, they must manifest themselves in other than linguistic ways" (2002: 57). Forceville and UriosAparisi preferred to talk about different modes instead of ways. I will stick to their appellation. Forceville defines a mode as a "sign system interpretable because of a specific perception process" (2009: 22). On top of written and spoken language, metaphors can also occur in static and moving images, music, non-verbal sound and gestures (2009: 4). In addition to that, they also argued that metaphors can either be monomodal or multimodal: one single metaphor can be rendered through distinctive ways at the same time. 


\subsubsection{Monomodal Metaphor}

To begin with, monomodal metaphors are types of metaphors that are the most frequently encountered. They correspond to metaphors whose source and target domains are expressed predominantly in one of the modes mentioned above by Forceville and Urios-Aparisi (2009: 22). For example, all written texts are considered to be more or less completely monomodal as they solely involve written language (Forceville 2016: 13). Thus, if one is reading a piece of poetry and stumbles upon a metaphor, chances are high that this one would be a monomodal metaphor. Nonetheless, communication in another media is less often so completely monomodal. If we take the visual mode for instance, it is more frequent to find multimodal metaphors in that mode since visual content is often associated with verbal elements, gestures or even sound depending on whether we are looking at moving images or not.

\subsubsection{Multimodal Metaphor}

In contrast, multimodal metaphor is defined as a metaphor whose target and source domains are represented through a combination of modes. This is mostly the case for non-verbal metaphors (Forceville 2009: 25). Multimodal metaphors are particularly common in advertising and in the media. According to Forceville, a multimodal metaphor should meet the following criteria (Forceville 2009: 469):

(1) Given the context in which they occur, the two phenomena must belong to distinct categories. 
(2) The two phenomena must take the form of a conceptual metaphor and can thus be illustrated by the schema A IS B.

(3) The two phenomena must appear in at least two different modes.

Olena Morozova wrote that "multimodal metaphors appeal to the emotional sphere while verbal metaphors predominantly appeal to reason" (2017: 272). According to her, multimodal metaphors are said to be emotionally denser than verbal metaphors since they are supposed to be more connected to the emotional sphere than verbal metaphors. This argument is debatable since all metaphors, whatever their modes, are said to arouse emotions. For instance, a verbal metaphor found in a poem would probably appeal more to emotions than reason, although monomodal.

The use of spoken language is often multimodal as it involves not only oral production of sound but also the reproduction of gestures that can be visually perceived by the addressee (Muller and Cienki 2012: 298). Consequently, we can often encounter multimodal metaphors in discourse if someone uses a metaphor and makes a gesture that corroborates the metaphor he verbally employed. For instance, if someone says we have to look at the bigger picture and makes a square with their fingers when pronouncing the word picture, this would be an example of multimodal metaphor as the word picture is here metaphorical and it is rendered into two modes, namely, spoken language and gesture. Interestingly enough, we know that in speeches, such as political speeches, a great importance is given to kinaesthesia, and it is a vast area of study for searchers in the field of communication. Gesture metaphors can be studied, prepared in advance and used to reinforce verbal expressions. 
In brief, the study of multimodality in the case of metaphor strongly supports Lakoff and Johnson's claims that metaphors should not only be considered as literal processes but are, indeed, pervasive in our everyday life (Muller and Cienki 2012: 219). They are involved in the way we think as well as the way we talk.

\subsubsection{Visual Metaphor}

A visual metaphor is a metaphor expressed through a visual mode such as a photograph, a drawing, a moving image. They can be either monomodal or multimodal. They are frequently encountered in newspapers and advertisement. We can note that many newspapers articles dealing with Brexit feature pictures and cartoons that can be classified as visual metaphors, I will analyse a couple of examples in my corpus analysis.

Visual metaphor works in the same way as linguistic conceptual metaphors do. The major difference lies in the fact that instead of transferring words from one source concept to another, it is images that are transferred. Francisco Yus defined visual metaphor as "a mapping of information from one image to another, which we have called source image and target image respectively" (2009: 156).

To illustrate this category, here is a visual metaphor of Winston Churchill represented as a bulldog by cartoonist Henri Guignon. This is an American propaganda poster which was issued in 1940 following Franklin D. Roosevelt's election is the United States. By confectioning this poster, Guignon wanted to warn Americans that Churchill was the last "bulwark against totalitarianism" (Hall 2000: 18). 


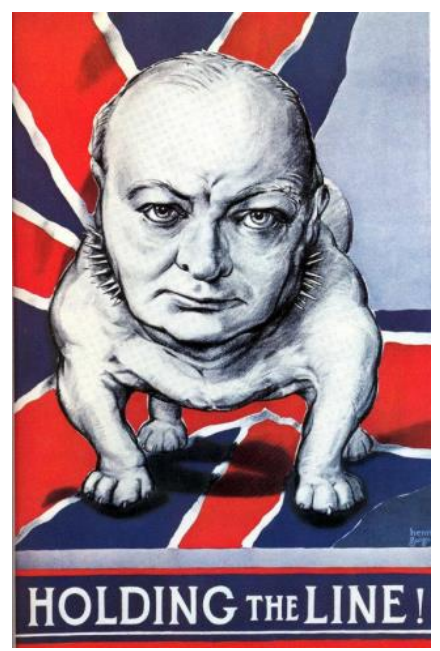

Moreover, Churchill was frequently nicknamed the British Bulldog due to the fact that people believed he had some physical traits in common with this dog breed, both physically and mentally. The legend says that his personality was as tenacious as one of a bulldog and bulldog are often said to be defensive and aggressive, which justifies Guignon's warning.

In this picture, both the source and the target domain of the metaphor can clearly be identified as they are both clearly depicted. This example of visual metaphor corresponds to a case of what Forceville labelled hybrid metaphor. According to him, a hybrid metaphor is a metaphor whose source and target domains are both integrated within the mode. Both domains can be identified, but they form one single entity, and they cannot be untangled (2015: 8). In the example above, the source domain is the dog which stands for Churchill's body, and the target domain is Winston Churchill himself, whom one can figure out thanks to his face. Here, both domains do form a single entity as they constitute a whole.

This sort of hybrid animal, halfway between a dog and a human being is quite striking at first sight, and this is what makes visual metaphors so original. Seeing a four-legged animal with a familiar human face is quite incongruous, and this is this 
type of incongruity that allows the reader to shift from a denotative interpretation to a connotative metaphorical interpretation (Forceville, 1996: 115). It alerts the viewer that something is wrong and that this seemingly wrong thing needs to be decoded in order to be able to understand the whole picture. In an article dealing with visual versus verbal metaphors, Francisco Yus argued that "many visual metaphors are original in the way they create a metaphoric link through an anomalous visual arrangement" (2009: 166). He also argued that pictures would have a more powerful impact (2009: 168), which is a plausible thesis since visual metaphors allow us to directly visualise the concepts that are at the heart of the metaphor and impose on us a mental picture. Besides, the author of a visual metaphor is also able to convey the image they want their audience to get in mind, and that is what makes visual metaphors so powerful. With visual metaphors, mental pictures are imposed in the mind of the message receiver. In the case of linguistic metaphor, a mental picture is also constructed in the mind of the person who reads or hears it but it may vary according to each individual so it may not have the same impact and not convey the exact same meaning. 


\subsection{Functions of Metaphor}

Metaphors do not perform the exact same function depending on the context. Contrary to the popular belief that predominated for many centuries, metaphor is not merely a figure of speech used for poetic purposes, although in some context it can be.

\subsubsection{The Cognitive Function}

The cognitive function is the most relevant one since my study is based on the cognitive approach to metaphor. According to cognitive linguists, metaphors can be apprehended as conceptual instruments that allow people to understand and experience one kind of thing in terms of another (Lakoff and Johnson 1980: 5). Thus, metaphors can be considered as a tool that allows people to think about situation that are new, complex or remote (Chilton and Ilyin 2009: 9). In Language, Mind and Culture, Kövecses argued that there are three different functions that commonly occur at the same time and together form the cognitive function of metaphor $(2006$ : 128). Firstly, some metaphors are structural. They are used to impose some structure on the target domain thanks to the mapping that is characteristic of metaphors. Metaphors whose target domains are abstract entities such as LOVE IS A FIRE and LIFE IS A JOURNEY often fall into this category of structural metaphor. The source domain of structural metaphors provides a rich structure to talk about and understand the target domain. In other words, framework metaphors allow us to use one highly structured concept to structure another that is less delineated (Lakoff and Johnson 1980: 62). 
Secondly, some metaphors provide an ontological status for the target domain. In other words, when the target domain refers to something intangible, it has no presence, and it cannot be grasped such as processes, actions and states, metaphors can be used to specify their existence, to represent them in concrete terms (Kövecses 2006: 128). For example, the mind is often conceived as a machine, especially when using expressions such as my brain isn't functioning today. In that case, an ontological metaphor is used to represent the mind with more concrete terms.

Moreover, in the Conceptual Metaphor Theory, personification is regarded as a type of ontological metaphor as it consists in talking about a non-human abstract entity in terms of human actions and characteristics (Semino 2008: 101). According to Lakoff and Johnson in Metaphor We Live By, personification is an important and pervasive type of metaphor because it involves human beings as the source domain (1980: 33).

Lastly, some kinds of metaphor are used to organize concepts with respect to one another (Lakoff and Johnson 1980: 16). These are called orientational metaphors. They give spatial orientation to a concept, as it is the case for the metaphors MORE IS UP and LESS IS DOWN, for instance.

\subsubsection{The Ornamental Function}

Even though we have been strongly supporting the fact that metaphor is not uniquely a way to give colour to a text but is deeply rooted in our conceptual system, we must admit that in some contexts, metaphor is, indeed, a simple figure of speech. 
Ornamental metaphor is the type of metaphors described by Aristotle and by most writers preceding conceptual theories and the discovery that metaphor is deeply engrained in our conceptual system. Numerous examples of ornamental metaphors can be found in literature. As an illustration, we can take a look at Dylan Thomas' famous poem Do Not Go Gentle Into That Good Night is which he used the metaphor of the night as a euphemism to express death:

Do not go gentle into that good night.

Old age should burn and rave at close of day;

Rage, rage against the dying of the light.

Using a metaphor as an ornament allows poets and writers to give more depth to their writings. It provides the reader with beautiful and lyrical mental pictures and it also arouses emotions. And as mentioned by Lakoff and Johnson: "Great poets can speak to us because they use the modes of thought we all possess", that is, metaphors. (1989: $x i)$.

\subsubsection{The Didactic Function}

Since they are so strongly associated with visualisation and mental representation, metaphors can be considered as great tools for us to understand complex and abstract topics. Metaphors can be used as a way to simplify a statement or an idea. It explains why metaphors are so frequently encountered in children's books for instance - either educational or literary books. Lori D. Bougher stated that "analogical reasoning [such as metaphor], involves the adoption of a familiar source or experience to serve as a base analogue that is then mapped onto an unfamiliar 
target analogue" (2012: 146). So according to her statement, metaphors can be seen as having a didactic function since the analogy that it produces relies on familiarity, the source domain being this familiar thing. Metaphors allow us to understand a target domain thanks to an analogy with something that is familiar to us as the source domain. As she wrote: "one of the greatest resources individuals has to help them understand the world, in general, is to draw from what they already know" (2012: 146). For instance, children are often taught subtractions and additions with metaphors involving sweets, the sweets being a metaphor representing the numbers. This proves to be efficient to teach mathematics to kids because this a situation which is likely to be familiar to them. Furthermore, the didactic function of metaphor can also be used by politicians when they address their audience about complex topics such as thhe economy as they want to make sure that their audience understand what they are saying if they want to be convincing.

\subsubsection{The Persuasive Function}

Another slightly subtler function that metaphors can take on is a persuasive function. It can account for the fact that metaphors are so frequently encountered in advertisement and political discourse. Jonathan Charteris-Black wrote a book entitled Politicians and Rhetoric in which he studied the persuasive power of metaphor in rhetorical discourse. He argued that "metaphor influences our beliefs, attitudes and values because it uses language to activate unconscious emotional associations and it influences the value that we place on ideas and beliefs on a scale of goodness and badness" (2005: 13). Two important notions can be found in this 
quote. First of all, it highlights the idea that metaphors arouse emotions, and emotions are essential elements of a persuasive discourse. As stated by Aristotle in Rhetoric, successful rhetoricians should be able to arouse feelings, hence to use pathos, and using metaphors is a way for them to do so. Charteris-Black defined metaphors as "emotion-arousing bearers of meaning"; he particularly insisted upon the fact that metaphors shape the way we understand the world and understand our feelings about it (2005: 14). He paid particular attention to emotional response that metaphors can generate.

Furthermore, metaphors can also be persuasive thanks to the connotations they engender. As stated earlier, metaphor can convey a positive or negative association to an entity depending on the source domain it is associated with. Charteris-Black wrote: "metaphorical meaning is determined by connotations aroused by the words in their literal use" (2005: 14). This corresponds to the notion of semantic prosody. For Bill Louw, semantic prosody refers to "a consistent aura of meaning with which a form is imbued by its collocates." (1993: 157) For example, in 2015, David Cameron did an interview about the Calais crisis in which he described migrants as "a swarm of people coming across the Mediterranean, seeking a better life, wanting to come to Britain". Using a metaphor that compares migrants to animals possibly triggers negative associations in the mind of the person who receives this message, hence making them feel that migrants are bad. Depending on the political party, the word immigrant is often associated with words with a derogatory connotation. Consequently, its semantic prosody is negative. 


\section{Conclusion}

In short, it can be assumed that during the last century, studies on metaphor have completely reshaped our vision of this phenomenon. What was first considered as a simple figure of speech used as an ornament turns out to be a central point in our everyday life, for it shapes our conceptual system. The most crucial point raised so far is the fact that not only do we speak metaphorically but we think metaphorically, without even realising it most of the time. Now that we have laid out the theory, let us dig further into my topic by investigating the role of metaphor in political discourse. Besides, it is important to add that one given metaphor can endorse different functions depending on which context it appears. Then, ascribing a function to a metaphor highly depends on its context. That is to say, one metaphor's function may vary depending on the context in which it features. 


\section{Part II: Metaphor and Political Discourse}

\section{Introduction}

"Political language [...] is designed to make lies sound truthful and murder respectable and to give an appearance of solidity to pure wind" (Orwell 1946: 157). This quote denouncing the corruptive use of language in politics perfectly illustrates how language and politics are intimately linked. Language and politics are two inseparable entities. Language is often considered as politicians' main weapon. As noted by Paul Chilton: "political activity does not exist without the use of language" (2004: 6). Politicians perform their power through the use of language.

This part will provide an overview of political communication and an explanation illustrating why language is so important in politics. It will build the bridge that unites the domains of politics and language. It will particularly focus on why politicians use metaphors in their discourse and what their purpose is in doing so.

\subsection{Politics and the Use of Language}

According to Aristotle in Politics, language evolved to perform social functions. He also considered human beings as "political animals" by nature due to the fact that they are granted the power to speak. By claiming this, Aristotle was the first person to uncover how strong the relationship between politics and language is. He wrote: "Man is a political animal, in a sense in which a bee is not. Nature does nothing without some purpose; and she has endowed man alone among the animals 
with the power of speech." (1253a 1-18, 1987). What he meant by that is that human beings are, by nature, meant to live in a state, and by state I mean a political community with a form of government at its head. Yet, this type of organisation can only be achieved through the use of language. Thus, language allows us to perform our true nature; we use it to organise our social existence (Joseph 2006: 3). However, in the configuration of a state, there is necessarily some kind of hierarchy. It means that some people are superior to others; some have more power over others. What is more, it is language that allows us to establish this sort of hierarchy, at least, partly. Politicians who master language the best are those who manage to reach higher positions in the social hierarchy. For instance, those who are elected as presidents were able to be so because they managed to persuade a large part of the population, which sometimes represents thousands of people. According to Charteris-Black: "The most important type of behaviour by which leaders mobilise their followers is their linguistic performance. In a democratic framework it is primarily through language that leaders mobilise their leadership" (2005: 1). By stating so, Charteris-Black acknowledged that language is the way through which leadership is acquired and exerted. Besides, as argued by Umberto Eco in Faith in Fakes, nowadays, countries are controlled by those who control communication (1985: 127). Communication, hence language, is central to leadership and power. Communication does not solely equal language, but language is definitely a means of communication, if not the main one.

Some even argue that political language is a different type of language since it differs from the language spoken by a majority of people, and from the norm (2004: 12). Political language calls upon rhetorical devices and linguistic elements that would not normally be used in a usual conversation between two persons. In fact, 
political discourse is built with the utmost care so as to leave a trace in the memory of the reader or hearer. This is partly for this goal that linguistic elements such as metaphors, but not only, are used. For instance, one of the greatest political speeches delivered that everyone knows about is Martin Luther King's I Have a Dream speech. Aside from the fact that it was rapidly considered as a milestone in the History of America regarding the historical context in which it took place, part of the fame owned by this speech is due to the way it was articulated. The extensive use of anaphora is one of the elements that made this speech so powerful and so striking, among other elements, of course. What I mean is that although not everyone would be able to render the content of this speech, what it is talking about or the context, most of us knows about this famous anaphora "I Have a Dream". It shows that linguistic devices influence greatly how political speeches are perceived. But it also illustrates the fact that political discourse differs from everyday language, by the language spoken by the majority of people.

Consequently, political discourse is considered as a subcategory of discourse. According to Fatih Bayram, political discourse is a result of politics and it is historically and culturally determined. It fulfils various functions due to different political activities." (2010: 5, 6) Politicians use discourse to persuade, to express their ideology, to legitimise their power. These are examples of functions fulfilled by political discourse. More specifically, rhetoric is at the heart of politics. Rhetoric is defined as "the ability to see in each case the available means of persuasion and of finding the way to appeal to the emotions of the audience" (Kennan 2001: 20). Politicians strongly rely on rhetorical tools, especially in times of crisis and defining moments, such as euphemisms and dysphemisms, figures of speech, and, of course, 
metaphors. Generally speaking, it seems that rhetoric is an essential part of political culture (De Landtsheer 2007: 57).

To go further, language is decisive for politicians who desire to acquire power as it is what they will be judged upon. The language they use will convey a certain image of themselves, and then voters are free to decide whether they like this image or not, hence if they want to support this person or not. During a presidential campaign, politicians will be judged almost entirely rely on their words, on what they say, on what they promise during TV debates and manifestoes for instance. Their words will guide our choice, hence the importance given to the choice of words and how they articulate their discourse. This coincides with the principle of ethos as mentioned by Aristotle in Rhetoric, and that will be further developed in the following subpart.

\subsubsection{Persuasion and Rhetoric: Aristotelian View}

The main target of politicians is to persuade people. In Comparative Government and Politics, Rod Hague wrote: "politics involves reconciling differences through discussion and persuasion. Communication is therefore central to politics" (1998: 3-4). Persuasion, as well as language in general, is central to politics. In fact, both language and persuasion go hand in hand as persuasion requires the use of language. Persuasion can be defined by the art of using linguistic tools in order "to change the thinking or behaviour of an audience or to strengthen its beliefs" (Virtanen and Halmari 2005: 3). In other words, persuading someone means influencing their beliefs through the use of language. This is the subtle power that 
politicians possess and exert over us. Persuasion is performed through rhetoric since rhetoric refers to the art of persuading. For Charteris-Black, the difference between rhetoric and persuasion is the following: "rhetoric refers to the act of communication from the hearer's perspective while persuasion refers both to the speaker intentions and to successful outcomes" (2006: 9). Hence, rhetoric does not necessarily end up persuading; it can be unsuccessful if not performed efficiently.

It is true that in order to perform their power through language, politicians generally appeal to the three rhetorical spheres as described by Aristotle in Rhetoric, that is: ethos, logos and pathos. Logos corresponds to the use of rational and concrete argument; it is generally linked to reason. Ethos is the presentation of the character as trustworthy; it refers to the image speakers convey of themselves as they speak. Pathos refers to the emotions raised by speakers in the audience (De Landtsheer 2007: 57). This is regarded as “Aristotle's main tool for conceptually analysing the process of persuasion" (Shields 2012: 596). This configuration is usually represented via an equilateral triangle such as the one that follows:

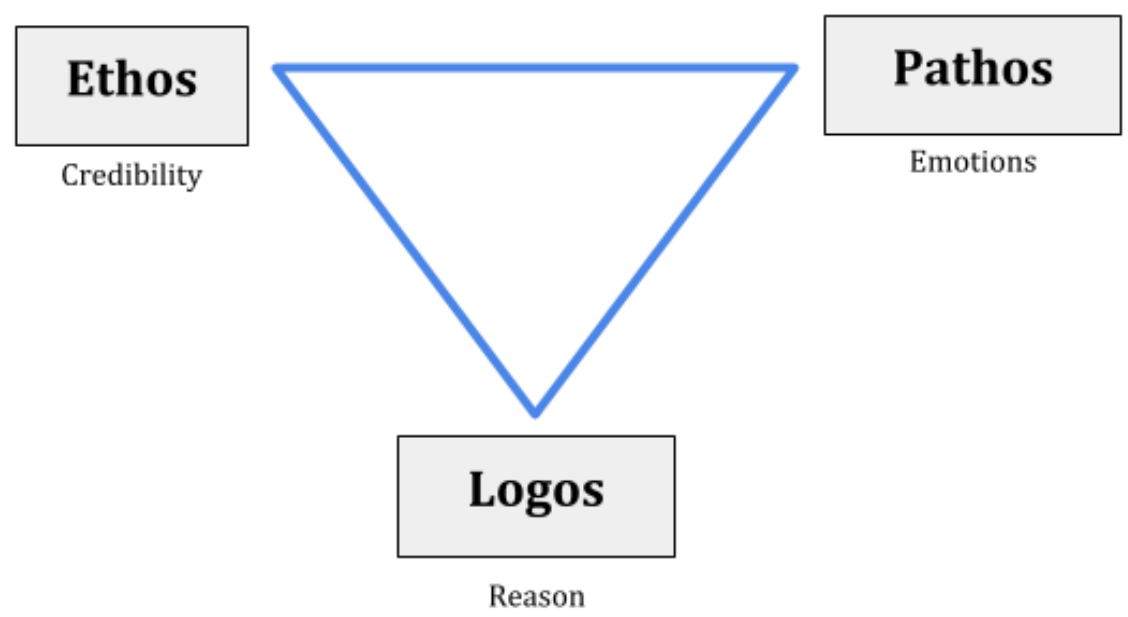

Figure 4: Aristotle's Rhetorical Triangle 
These are the three factors to be taken into account in order to persuade someone efficiently according to Aristotle's theory. The three elements of the triangle are all equally important, hence the equilateral triangle. For a discourse to be persuasive, speakers have to take into account both the type of language they use, and the type of behaviour they exhibit when delivering their speeches to the audience. This theory is still taught and used nowadays as a persuasive strategy, and it can still be found in political discourses. For the present study, the most important element to focus on is pathos since pathos often involves figurative language, hence metaphors. 


\subsection{The Use of Metaphors in Political Discourse}

\subsubsection{Conceptual Metaphor Theory Applied to Politics}

The primary reason as to why politicians use metaphors in their discourse is probably linked with the theory of the conceptual metaphor. According to this theory, the main reason why metaphors exist is due to their cognitive function. Conceptual metaphors help us understand complex and abstract topics. In a recent interview, Charles Forceville declared that the origin of metaphorical language lies in the fact that "we need metaphors because they are the only way in which we can conceptualise abstract and complex things" (2018). The same reason can explain the widespread use of metaphors in politics as most topics tackled by politicians are somehow abstract. The nature of language in itself constrained them to use metaphors when talking about topics related to money or international affairs for instance. Thompson holds that:

"The world of politics is complex, value-laden and both cognitively and perceptively removed from everyday experience [...] A major function of political metaphor is to link the individual and the political by providing a way of seeing relations, reifying abstractions, and framing complexity in manageable terms." (1996: 185)

Accordingly, political metaphors are of particular interest for us as they help us understand political discourse and they allow us to be on the same wavelength as politicians. In this context, the metaphors more likely to be encountered will be lexicalized and rather neutral. However, sometimes, politicians will make the most of this linguistic constraint to use metaphors that will describe these issues in a connoted way to perform other functions, such as persuading. 


\subsubsection{Metaphor and Persuasion}

Metaphors can be considered as effective means of persuasion since they are linked to emotions; and emotions or pathos for Aristotle, is one of the essential parts of the art of persuasion. Italian philosopher Francesca Rigotti who wrote an article about political theories and metaphors claimed that metaphors play a fundamental part in political discourse. She compared metaphors to passwords that would invite the addressees to enter a structure of thought that is familiar to them (1990: 549). It is true that metaphors are based on familiarity, especially following the conceptual metaphor theory. As mentioned in Part I, metaphors allow us to understand one domain of experience usually unknown in terms of another one that is supposed to be more familiar. Consequently, metaphors in political discourse can, indeed, be regarded as some sort of password or key that would allow us to understand political discourse based on what we know and what we have already experienced. In addition, Rigotti raised a particularly interesting point so as why metaphors are so frequent in politics. She declared that political language does not have literal words to talk about its own subject, hence the use of figurative language and words borrowed from other domains including the domain of religion (1990: 550). The full veracity of this statement can be argued, and it can be opposed to Gerard Steen's point of view. In contrast, Steen claimed that "metaphor is used deliberately when it is expressly meant to change the addressee's perspective on the referent that is the target of the metaphor by making the addressee look at it from a different conceptual domain" (2008: 222). This seems to be a more realistic approach as it seems that sometimes, politicians can use metaphors on purpose to generate added effects such as raising emotions for instance. According to Jonathan Charteris-Black, 
metaphors would act as "emotion-arousing bearers of meaning". His argument is the following: "metaphors influence our beliefs, attitudes and values because they activate unconscious emotional associations" (2005: 14). That is, metaphors create emotional associations depending on which domain the target domain is associated with and what sort of connotation is aroused by the source domain. This can be associated with the notion of semantic prosody. This notion defines the fact that some words may acquire a negative or a positive connotation depending on the domain they are associated with. Then, the connotation will possibly trigger emotions from the person who is to decode the metaphor. As an illustration, we can consider Enoch Powell ${ }^{3}$ 's notorious speech known as the "Rivers of Blood speech" in which he denounced mass immigration by comparing the Chanel to "the River Tiber foaming with much blood". Associating migrants with "blood foaming" conveys a derogatory connotation associated with migrants and migration. Using such a metaphor may be interpreted as a way for Powell to try to persuade his audience that immigration was harmful for the country. It also indirectly uncovers his political stand on the question. This is done with much delicacy as metaphors are generally insidious. Most of the time, they remain unnoticed and yet they are pervasive in language in general, including political discourse, which adds a little more to their persuasive power.

The last point I would like to mention to show that metaphors can be considered as persuasive tools is Jonathan Charteris-Black's argument that metaphors create a link between the addressee and the addressed. He wrote: "Engaging in the act of stretching the resources of language involved in metaphor is

\footnotetext{
${ }^{3}$ British politician and Member of Parliament. He is remembered for his opposition to the UK entering the European Economic Community and his virulent remarks about the non-white British citizens. (britannica.com)
} 
a way of forging a stronger interpersonal bond between the speaker and hearer that extends beyond simply poetry" (2004: 12 ). What he meant is that decoding a metaphor creates a bond between the two persons or groups of people involved in the process as metaphors speak to "the voice within."

All in all, this quote from John Locke that features in Essay Concerning Human Understanding denouncing the role of figurative language summarizes the big lines of my argumentation:

"But yet if we would speak of things as they are, we must allow that... all the artificial and figurative application of words eloquence hath invented, are for nothing else but to insinuate wrong ideas, move the passions, and thereby mislead the judgment, and so indeed are perfect cheat" (1950: 146)

Metaphors can indeed be considered as "artificial and figurative application of words eloquence." However, there is one point that needs to point nuanced in this quote. As argued in Part I, metaphors are not exclusively a matter of words and language. Therefore, the "nothing else" might be a little exaggerated. But it is true that metaphors, especially in political discourse, are there to insinuate wrong ideas, move the passions and mislead the judgement.

\subsubsection{Metaphor and Ideology}

Metaphors are also a way for politicians to hide their ideologies so as to convey them more indirectly. My definition of ideology matches Charteris-Black's in Politicians and Rhetoric. He defined it as "a belief system through which a particular social group creates the meaning that justifies its existence" (2006: 21). For instance, in this study, two ideologies confront each other: the ideology promoted by 
those who were in favour of Brexit, and those who think Brexit was a bad idea. Two social groups were then created: The Leave and the Remain campaign.

Discourses, political discourses included, reflect particular ideologies, but as pointed out by Elena Semino, discourses also contribute to shaping ideologies, and change them. This can be achieved by the use of metaphors. In politics, most metaphors unveil a political tendency as they are scarcely mere coincidences (Rigotti 1990: 559). It is true that metaphors are not neutral, Elena Semino claimed that "constructing something in terms of something else results in a particular view of the something in question" (2008: 32). They tend to hide their ideas and opinions on topical issues behind conceptual metaphors. Metaphors often reveal a great deal about the ideology of a community (Dirven 1990: 566), and that is why studying political discourse from a linguistic perspective is of much interest. Analysing metaphors allows us to deciphere the true meaning conveyed by politicians in their discourse. Politicians hide their truth behind metaphors; truth in the sense of Nietzsche, that is: "truths are illusions about which one has forgotten that this is what they are; metaphors which are worn out and without sensuous power" (1999: 146).

In addition, metaphors are useful tools for politicians to convey their ideologies and criticise the ideologies of their opponents since they can play on the hiding highlighting principle. The use of conceptual metaphors allows them to depict their ideologies in a fashion that is flattering while depicting their opponents' ideologies in a derogatory way. It all depends on the domains they use to build their metaphors. For example, politicians from the Leave campaign will certainly be more likely to use metaphors with some negative source domains to talk about Europe. 


\subsection{Analysing Metaphors in Discourse: Critical approaches}

Before digging into the analysis of my corpus, I would like to give a brief overview of a couple of critical approaches to discourse and metaphors that proved to be particularly popular in the domain of conceptual linguistics. First, I will introduce the Critical Discourse Analysis before moving on to the Critical Metaphor Theory.

\subsubsection{Critical Discourse Analysis}

Critical Discourse Analysis (CDA) is a branch of applied linguistics strongly associated with Cognitive Linguistics. The emergence of this paradigm is notably due to the works of Norman Fairclough and Teun van Dijk. It is concerned with the study of the relation between discourse and power. More specifically, van Dijk described it as follows:

Critical Discourse Analysis (CDA) has become the general label for a special approach to the study of text and talk, emerging from critical linguistics, critical semiotics and in general from a socio-politically conscious and oppositional way of investigating language, discourse and communication [...] CDA specifically focuses on the strategies of manipulation, legitimation, the manufacture of consent and other discursive way to influence the minds of people in the interest of the powerful (1995: 17).

In other words, CDA invites us to analyse political discourse in a critical way so as to decode the hidden ideology it conveys. Additionally, this method of analysis is particularly interested in the way social power abuse, dominance and inequalities are achieved in texts and talks in the political context (van Dijk 2008: 85). In other 
words, CDA invites us to analyse political discourse in a critical way so as to decode the hidden ideology it conveys.

Fairclough and Wodak summed up the main principles ascribed to Critical Discourse Analysis (1997: 271-280):

(1) CDA addresses social problems.

(2) Power Relation are discursive.

(3) Discourse does ideological work

(4) Discourse constitutes society and cultures.

(5) Discourse is historical.

(6) The link between text and society is mediated.

(7) Discourse analysis is interpretative and explanatory.

(8) Discourse is a form of social action.

What is more, this approach to discourse analysis is of particular interest for this thesis as it considers metaphors as a phenomenon of particular significance (Hart 2007: 109). According to Jonathan Charteris-Black: "metaphor is central to Critical Discourse Analysis since it is concerned with forming a coherent view of reality" (2004: 28). Metaphors are particularly tied to Critical Discourse Analysis as it can be regarded as a tool employed by politicians to hide ideology and as explained in part 2.3.2 and to persuade people. Thus, it contributes to the "strategies of manipulations" and "ways to influence the minds of people" that CDA specifically focuses on. Moreover, Kieran O’Halloran argued that “one aspect of CDA involves highlighting how metaphors can be ideologically significant - how metaphors can help construct in the mind of the reader or listener, the nature of the events or situations being described" (2007: 160). It is true that metaphors allow us to create a mental picture of a certain reality as it makes the abstract concrete for instance. As stated by Aristotle, "metaphors set the scene before our eyes" (1954: 1410b). This is 
to be coupled with the fact that, as mentioned previously, metaphors can be used by politicians to manipulate the perception one has of a certain issue in more or less connoted way, either positively or negatively connoted.

\subsubsection{Critical Metaphor Analysis}

Critical Metaphor Analysis is a method of investigation that helps linguists analyse metaphors in discourse. More specifically, it is an approach to metaphors in discourse that aims to highlight the intentions and ideologies underlying in a discourse (Charteris-Black 2004: 34). It was mostly discussed by Charteris-Black in two of his books: Corpus Approaches to Critical Metaphor Analysis (2004) and Politicians and Rhetoric (2005). He explained that there were three stages to this type of metaphor analysis: identification, interpretation and explanation. To him, a metaphor can be identified in a given discourse because the words used metaphorically provoke semantic tensions as the words are used in an unusual context (2005: 26). Then, the interpretation relies on the cognitive approach raised by Lakoff and Johnson. The third stage of the Critical Metaphor Analysis consists in uncovering the motivation for the use of the metaphor, explaining why such metaphor is used, what it tells about the utterer's viewpoint (Charteris-Black 2005: 28). This approach is particularly relevant as it suggests that metaphorical expressions used in discourse should be studied in context. As a matter of fact, interpreting a metaphor relies almost entirely on the context in which the metaphorical utterance appears.

Critical Metaphor Analysis is often thought about as the interface between the Conceptual Metaphor Theory and the Critical Discourse Analysis, although they 
might be some areas of tension between these two frameworks. Charteris-Black denounced that according to the Critical Discourse Analysis framework metaphors are "chosen by speakers to achieve particular communication goals within particular context rather than being predetermined by bodily experience" (2004: 247).

\section{Conclusion}

All in all, the global purpose of this part was to introduce the context of my study. It allowed us to get a better understanding so as why the study of political discourse is such an interesting task, especially discourse that is filled with metaphors. I have explored the different elements that politicians should rely on to make effective use of their persuasive power. The conclusion which can be drawn from that is that politicians are able to dominate and control their public mostly through the way they manage to articulate efficient speeches that raise our emotions and speak to us at an inner level, which generally involves metaphors as will be seen in the next part. 


\section{Part III: Case Study: Metaphors Shaping Brexit Discourse}

\section{Introduction}

These past few years, European politics has had to deal with a great wave of Euroscepticism coming from all parts of the EU. It started in Greece, reached France and hit Britain. This turnaround reached a peak when the British government decided to actually take concrete actions and decided to propose a referendum on the EU membership in 2016, which led to an unexpected event: Brexit. This part will provide an understanding of the context surrounding my research before digging into my corpus analysis. I will try to investigate on what Brexit refers to and what people mean when they talk about Brexit.

\subsection{Research Questions}

First and foremost, it is important to set out the underlying purpose of my research. The main questions I will try to answer and which will guide my research are the following: what are the metaphors used to depict Brexit and how do they give meaning to this event? In other words, this thesis aims to find out and analyse what the concepts used by politicians in the European Union and in the United Kingdom to talk about Brexit are, starting from the premise that Brexit is an abstract entity modelled by words and by the way it is being talked about. From our main questions, other few questions may also raise our interest:

- What are the most common metaphors used by politicians in their communication concerning Brexit? 
- Can these metaphors be classified according to the Conceptual Metaphor Theory?

- What are the source domains used to generate the metaphors?

- What image(s) do they convey?

- Do the source domains vary depending on factors such as time, place and political stance?

- Do verbal and visual metaphors portray Brexit in the same way?

- Do these metaphors shape the way we perceive Brexit?

These are the questions I will try to address in this thesis. 


\subsection{Contextualisation: A Few Words about Brexit}

To begin with, I will briefly set out the context of analysis by giving a rapid overview of the events leading to Brexit, the issue of the referendum and what awaits Europe and the United Kingdom now. In this part, I will define Brexit from a historical and etymological point of view. This will help us understand the elements constituting the corpus for this research.

\subsubsection{Etymology}

The word Brexit derives from another word of the same kind: Grexit. The term Grexit was coined in early 2012 by William Buiter and Ebrahim Rahbary, two members of Citygroup, an American multinational investment bank, who wrote an article about the possibility of Greece leaving the European Union. From a lexicological point of view, Grexit is the result of a word-formation process called blending. This process consists in the juxtaposition of two autonomous lexical bases. In that case, Grexit is the juxtaposition of the words Greece and exit. Then, this word quickly spread out across Europe, with the help of Eurosceptic political groups, and gave birth to other derivatives such as Frexit and Brexit. According to the Oxford English Dictionary, the term Brexit corresponds to "the (proposed) withdrawal of the United Kingdom from the European Union, and the political process associated with it". The term Brexit was first used in 2012 in a blog post written by Peter Wilding on BlogActiv.eu". In this article entitled "Stumbling towards the Brexit", he wrote: "unless a clear view is pushed that Britain must lead in Europe at the very least to

\footnotetext{
${ }^{4}$ Blog platform dedicated to European affairs.
} 
achieve the completion of the single market then the portmanteau for Greek euro exit [Grexit] might be followed by another sad word, Brexit". Notice the use of the determiner the in the title of the post. It is rather unexpected since it is the first time that this word is being used and nowadays we tend to only say Brexit. Thus, the word Brexit is an abstract noun as it refers to an action that has not yet entirely taken place, and which is still evolving.

\subsubsection{The EU Membership Referendum}

The relationship between the European Union and the United Kingdom has never been simple and idyllic, but rather a bumpy road punctuated by many ups and downs. There has always been some kind of anti-European feeling lingering over Britain. The United Kingdom was not part of the countries that founded the European Union. They even declined to join it in 1957 when they were proposed to. The EU-UK relationship started off on the wrong foot. A few years later, the United Kingdom changed their mind and decided to apply to join the Union in 1961, but their application was rejected twice by French President De Gaulle. They eventually managed to get integrated within the European Economic Community in 1973 thanks to Prime Minister Edward Heath. Paradoxically, the British were still quite uncertain and divided about this adhesion to the European Community. As a consequence, the British government decided to give the final say on whether the United Kingdom should remain in the Community or not by organising a referendum in 1975, which echoes the 2016 referendum. Although the issue of the 1975 referendum turned out to be positive by a vast majority $(67.2 \%$ voted to remain), the United Kingdom retained a unique status within the European Union. 
They have always been reputed for their singleness and their refusal to conform to European standards, such as the European currency. In fact, the case of the European Union has been a hot topic for debates at the heart of British politics ever since the end of World War II. This topic caused great divisions amongst British citizens and political parties, notably between the Conservative and the Labour parties. The Labour party generally supports the European Union whereas the Conservative Party is often associated with Euroscepticism, especially since the election of Margaret Thatcher, who was particularly renowned for representing the vision of a liberal Britain (Alexandre-Collier 2015: 2). All these past events paved the way for the situation we are now witnessing.

The first major event leading to Brexit can be traced back to 2011 when European leaders settled a new budget rules in order to resolve the financial issues the EU was facing at that time in the wake of the 2008 economic crisis. David Cameron, who was then Prime Minister of the United Kingdom, decided to veto Brussels's new financial plan, which gave rise to a new wave of Euroscepticism across the UK. Following this event and pushed by Eurosceptics who were determined to break away from Brussels, David Cameron took the risky decision to suggest a referendum on the EU membership in the hope to prove that Eurosceptics were minoritarian. However, the result did not turn out the way he expected it to be. David Cameron turned this suggestion of a referendum into the main argument at the core of his campaign for the General Election of 2015, even a promise. Thus, as he won the General Election, he had no choice but to respect his engagement and set out this referendum, even though Cameron was not in favour of Britain leaving the European Union. 
After receiving Royal assent in December 2015, Cameron declared that the referendum was to take place on 23 June 2016. After a long and heated campaign between the Remainers and the Brexiters and against all odds, the verdict was announced: the citizens of the United Kingdom decided to vote in favour of Brexit. The results were tight as the Vote Leave campaign won by $51 \%$ against $48 \%$ for the pro-Europeans. It was not a clear cut majority as was the case for the 1975 referendum. No one expected such results, neither in Britain nor in Europe, not even Cameron himself. The political situation of the country remained unstable and uncertain for a while. David Cameron had no other choice but to resign since his beliefs did not match the wishes of the country any longer. He stepped aside and Theresa May took back his seat in July 2016 a few days after the referendum. She now has the heavy responsibility of finding a compromise with the European Union so as to make the withdrawal from the European Union as smoothly as possible for both sides of the Channel. 


\subsection{Corpus Presentation}

As is the case for most linguistic studies nowadays, I have decided to adopt a corpus-based approach for my topic of research. My corpus will encompass both visual and verbal elements. To begin with, we will look at how Brexit is talked about in political speeches and legal documents dealing with the Brexit process. The elements constituting my corpus were chosen so as to render a global vision of Brexit in different countries and different periods of time. Then, I will analyse how Brexit is represented in visual contents, which will give me the opportunity to see if visual and verbal metaphors for Brexit convey the same image.

\subsubsection{Verbal Data: Presentation and Methodology}

The verbal data of my corpus is constituted of nine elements that will be carefully analysed. Among these elements, I have decided to include both written and spoken discourse. I have looked for metaphors in the last two Conservative party manifestos dating from before and after the referendum: in 2015 and 2017. It is interesting to compare them since they are not supposed to convey the same opinions on Brexit. In 2015, the Conservative Party led by David Cameron was trying to persuade people that Britain should remain in the European Union and simply renegotiate some parts of their adhesion, whereas in 2017 , the line of the party took a complete different path; this deviation was caused by the unexpected result of the referendum. In the 2017 Conservative manifesto, Theresa May aimed to persuade the voters that Brexit was the best decision the country could have taken and that the Conservatives were the most qualified to negotiate the best deal with 
the European Parliament in order for Britain to thrive outside the Union. Thus, doing a contrastive analysis of these two documents should be of much interest.

Then, I will go through Theresa May's letter to Donald Tusk ${ }^{5}$ which officially triggered article 50 of the Lisbon treaty, that is, the article that discloses the procedure that a European country should follow in order to legally withdraw from the European Union. The moment when Theresa May sent this letter was a key moment in the Brexit crisis as it accelerated the pace of the negotiations. The article stipulates that Britain has now two years to negotiate and find a compromise with the European Union before having to leave the European Union in 2019. Triggering this article also officialised the issue of the referendum, and made things slightly more real.

I will also analyse David Cameron's famous speech at Bloomberg Institute in January 2013. It is in this speech that Cameron officialised his will to set out a referendum on the EU membership, so it represents one of the first steps towards Brexit.

In addition, it is also interesting to study how Brexit is perceived in Scotland; especially how the Scottish Prime Minister talks about it, since, in Scotland, a majority of people voted to remain within the European Union and the Prime Minister herself was a strong militant for the Remain campaign. Even after the referendum, she kept expressing her disapproval on Brexit and Theresa May's decisions. Such was the case in the speech she made in January 2018, which is part of the corpus. On the same side of the argument, one of Jeremy Corbyn's speeches will be included. Corbyn is the leader of the main oppositional party in England - the Labour Party. As one of the major political figures in the country, it will be

\footnotetext{
5 President of the European Council.
} 
interesting to look at the way he described Brexit since he is known as being firm opponent to the Conservatives and Brexit.

In contrast, we shall not forget one of the most eminent figures of the proBrexit campaign, namely, Boris Johnson. I will study one of the speeches he made during the campaign just about a month prior the referendum in May 2015.

To finish with, we will study extracts from a plenary session on Brexit hold at the European Parliament in April 2017. We will focus our attention on speeches made by Guy Verhofstadt ${ }^{6}$, Nigel Farage ${ }^{7}$ and Michel Barnier ${ }^{8}$.

As regards the methodology I applied to the identification and analysis of the metaphors, here is how I proceeded: first, I read the documents and listened to the speeches in their entirety so as to get an overall impression. Then, I focused on the segments that deal with the topic of Brexit in particular. In each of these segments, I identified the possible metaphors related to Brexit. I decided to take into account all types of metaphors in my analysis, whether vivid, semi-lexicalised or lexicalised as described in Part I. However, I considered metaphors as conceptual when they occur several times across my corpus and when more than two occurrences could be classified under a given concept. The next step consisted in identifying the source domain of each metaphor. The metaphors were sorted out according to their source domains and the conceptual metaphors they can be ascribed to. Finally, I carried out a quantitative study to find out how many metaphorical expressions were present for each source domain. Then, I generated a graph from the figures in a chart, which allowed me to get the percentage of use for each source domain, for each element of my corpus. I added these charts at the end of each analysis. This final step allowed

\footnotetext{
${ }^{6}$ European Parliament's representative in the Brexit negotiations.

7 Leader of UKIP - Britain's nationalist party.

${ }^{8}$ European Chief Negotiator for the United Kingdom Exiting the European Union.
} 
me to see which domain is the most recurring to conceptualise Brexit and what image it conveys.

\subsubsection{Visual Data: Presentation and Methodology}

I also chose to include some visual data in my corpus so as to be able to study visual and multimodal metaphors representing Brexit. The choice of the visual elements to be included in my corpus follows a few steps. I selected three combinations of words related to Brexit, and I entered them into Google Images. The combination of words I came up with was: "Brexit", "Brexit; EU; divorce" and "Brexit; freedom". I selected one or two images per entry that I thought worth of interest and decided to examine them as follows:

(1) Spot the potential metaphorical elements in the picture.

(2) Try to reconstruct what the source and target domains are.

(3) Deduce what characteristics have been transferred from the source to the target domain.

(4) Give an interpretation of the overall metaphor. 


\subsection{Corpus Analysis: Visual Metaphors}

This is one of the pictures obtained by searching "Brexit" into Google images:

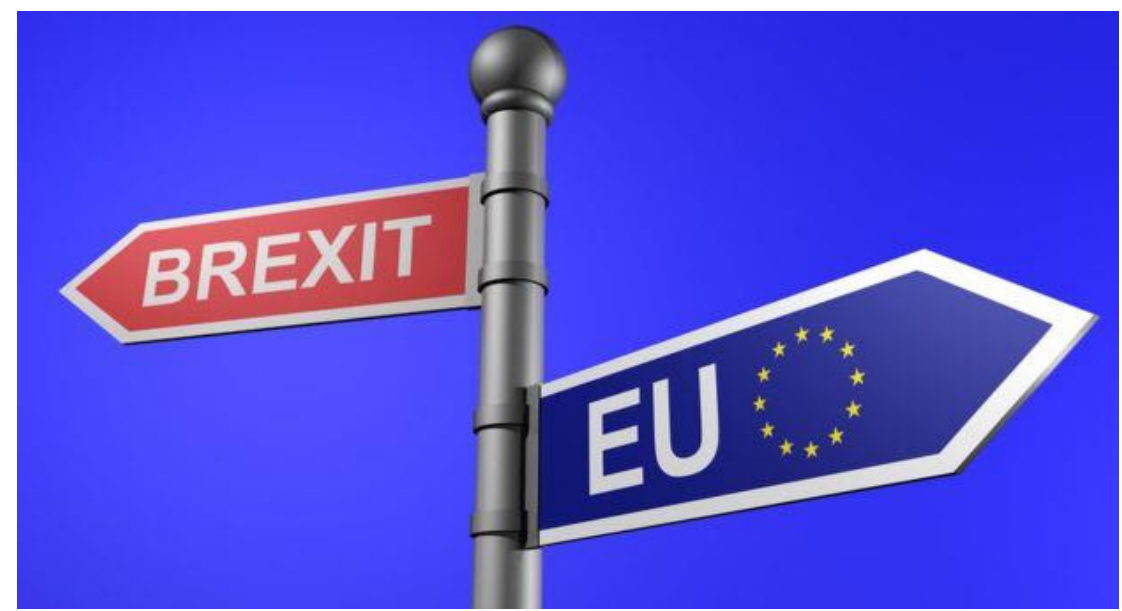

Figure 1. Image obtained by searching "Brexit" into Google Images. Image downloaded from http://www.bbc.com/news/uk-politics-32810887 in February 2018.

This image was downloaded from a BBC online article that sums up everything that needs to be known about Brexit. The metaphorical elements in this picture are the two road signs pointing in the direction of Brexit and the EU. The target domain is BREXIT, and the source domain is JOURNEY, giving the conceptual metaphor BREXIT IS A JOURNEY. This metaphor can be seen as a multimodal metaphor since the source domain is cued verbally but the target domain is represented visually by the road signs. The characteristics transferred from the source to the target domain include the fact that Brexit is seen as a process, an action, moving from a point (A) to another point (B). This visual metaphor illustrates the fact that Britain and the EU are now taking different paths; their relationship seems to be at a crossroads. Thus, in this picture, Brexit is described as a path leading to the separation of Britain and the EU. The ideological separation that led to Brexit is here represented by a physical separation. 
Here are the pictures we obtained for the entry "Brexit; EU; Divorce":

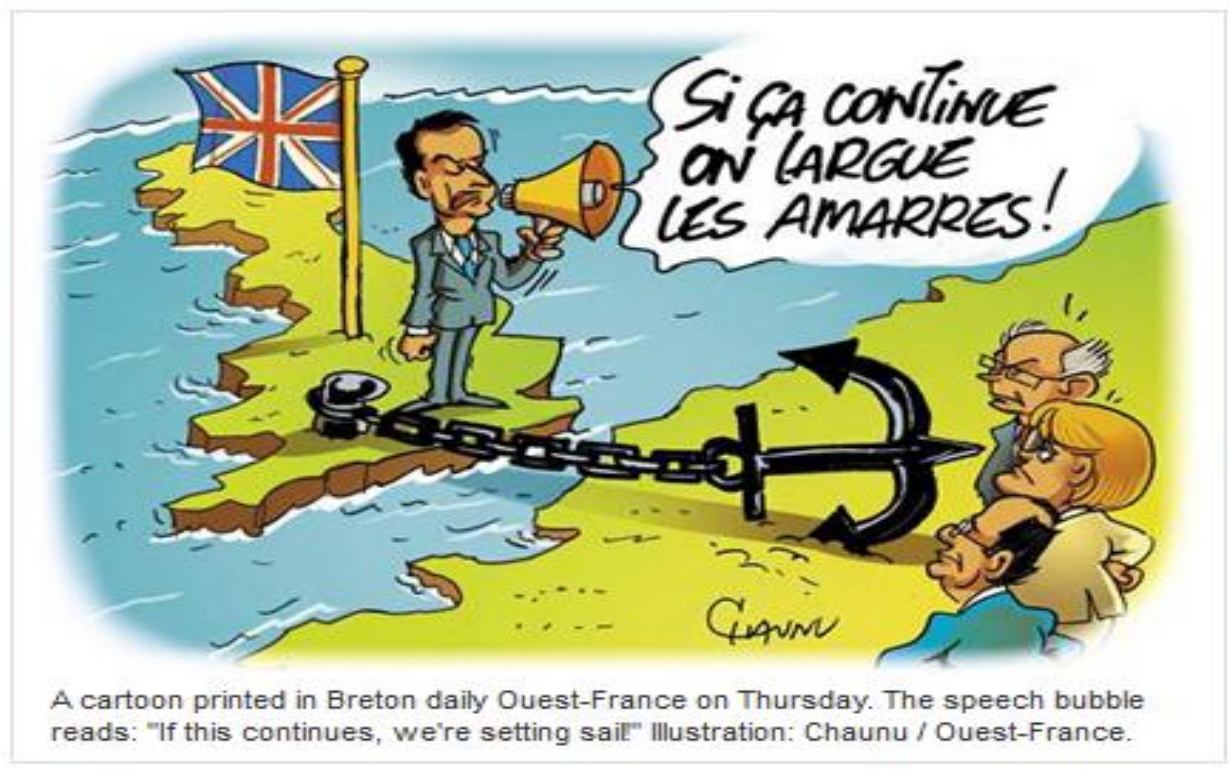

Figure 2. Image obtained by searching "Brexit; EU; Divorce" into Google Images. Image downloaded from http://beyond.blogs.france24.com/article/2013/01/24/david-cameron-franceeuropean-union-referendum-uk-exit-eu-0.html in February 2018.

This picture is a political cartoon drawn by Chanu published in a French newspaper Ouest France in 2013. We can identify David Cameron standing on the British isle talking to François Hollande, Angela Merkel and Jean Claude Juncker who are standing on the other side of the Channel, on the European continent. Cameron is threatening them to "set sail". Several metaphorical elements can be identified in this cartoon. The first striking element is the use of the domain of SAILING to talk about Brexit: both in the written and visual form. This is illustrated by the use of the expression larguer les amarres in David Cameron's speech bubble (meaning setting sail in English), which is usually used to talk about a boat. This same metaphor is also cued visually with the big anchor binding Britain to the continent. Brexit is then conceptualised as a cruise, giving the conceptual metaphor BREXIT IS A CRUISE. Another couple of conceptual metaphors derive from this one such as THE NATION IS A BOAT or THE PRIME MINISTER IS A CAPTAIN. The theme of sailing is a 
recurrent motif for the building of metaphors in politics and to talk about Brexit; we will get to see that further when analysing verbal data.

We could link this cartoon to Cameron's last speech as Prime Minister in 2016 following the issue of the referendum in which he compared himself as the captain of a boat who will try his best to "steer the country to the right destination".

However, we cannot say that this is a case of multimodal metaphor since both domains of the metaphor are in the same modes. The speech bubble hides both the source and the target domain and so does the drawing itself. This image seems to be a superposition of the same conceptual metaphor BREXIT IS A CRUISE expressed both verbally and visually. It seems that both verbal and visual metaphors complement each other; the visual might illustrate the verbal or vice versa. Yet, according to Roland Barthes in his article Rhetoric of the Image, the linguistic message that comes with an image generally aims to guide the interpretation of the image (1964: 44). He also stated that in cartoons, language and image are complementary (1964: 44.). So in this case, the verbal message could help the reader decode the visual metaphor.

This metaphor stresses the fact that Britain is an entity detached from the continent, it floats on its own and that it has quite a strong isolationist tendency strongly linked to Euroscepticism.

Even though it is not my initial object of study, I can also mention that this picture also involves a metonymy as the political figures represent their respective countries: David Cameron stands for the United Kingdom and Hollande, Merkel and Juncker represent the European Union. 
This is the second picture I chose for the entry "Britain, EU Divorce":

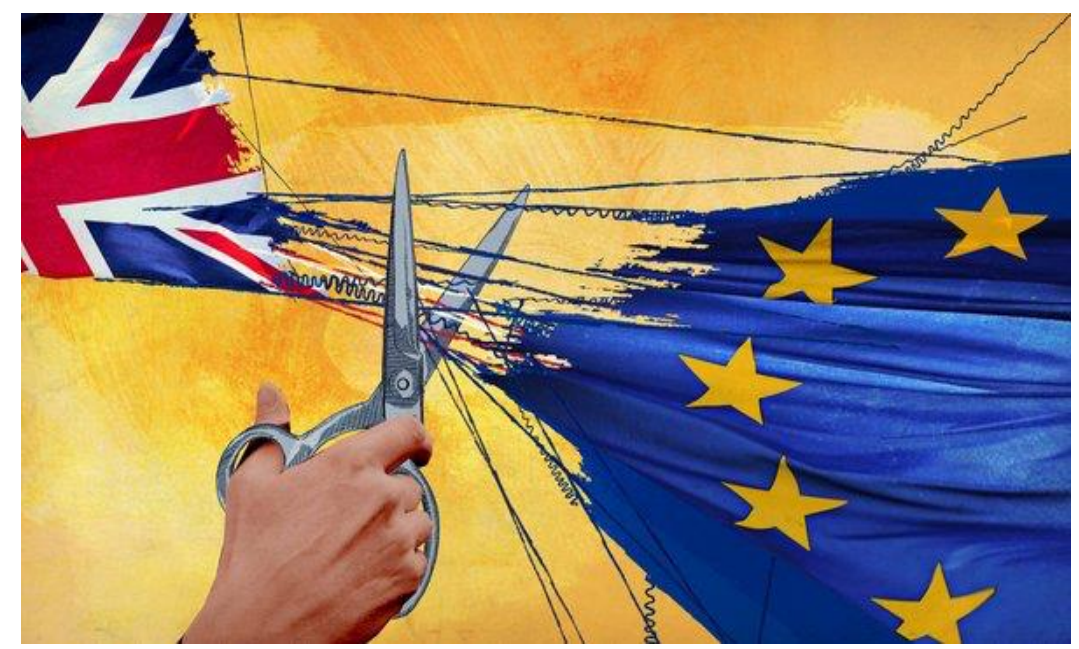

Figure 3. Image obtained by searching "Brexit; EU; Divorce" into Google Images. Image downloaded from http://eunotforme.com/index.php/245-uk-vs-eu-amicable-divorce in February 2016.

Here again, we can notice the use of metonymy as the two flags stand for their respective nations. It seems that metaphor is often combined with metonymy to form visual metaphors, at least in the case of visual metaphors involving countries. Olena Morozova likes to call this combination of metaphor and metonymy metaphtonymy (2017: 270). Isabel Negro Alousque came to the same conclusion in her corpus-based analysis of pictorial and verbo-pictorial metaphors in Spanish cartooning. She found out that a large number of metaphors are based on metonymy, and more precisely part for the whole metonymy (2014: 78).

Two metaphors can be considered in this image. On the one hand, there is the metaphor of the bonds uniting the United Kingdom to the European Union with the threads linking one flag to the other. This can be seen as a metaphor comparing the European Union as a piece of cloth made up of all the countries sewed together, but the stitching between the United Kingdom and the rest of the European Union is slowly coming undone. 
On the other hand, the pair of scissors can be seen as a metaphorical element representing Brexit that comes and cuts the remaining threads linking the European Union to the United Kingdom. These metaphors are both monomodal as their source and target domains are fully expressed in the visual mode. In addition, the hand holding the pair of scissors could be seen as the representation of the British citizens who voted to leave. This would also be a metonymy.

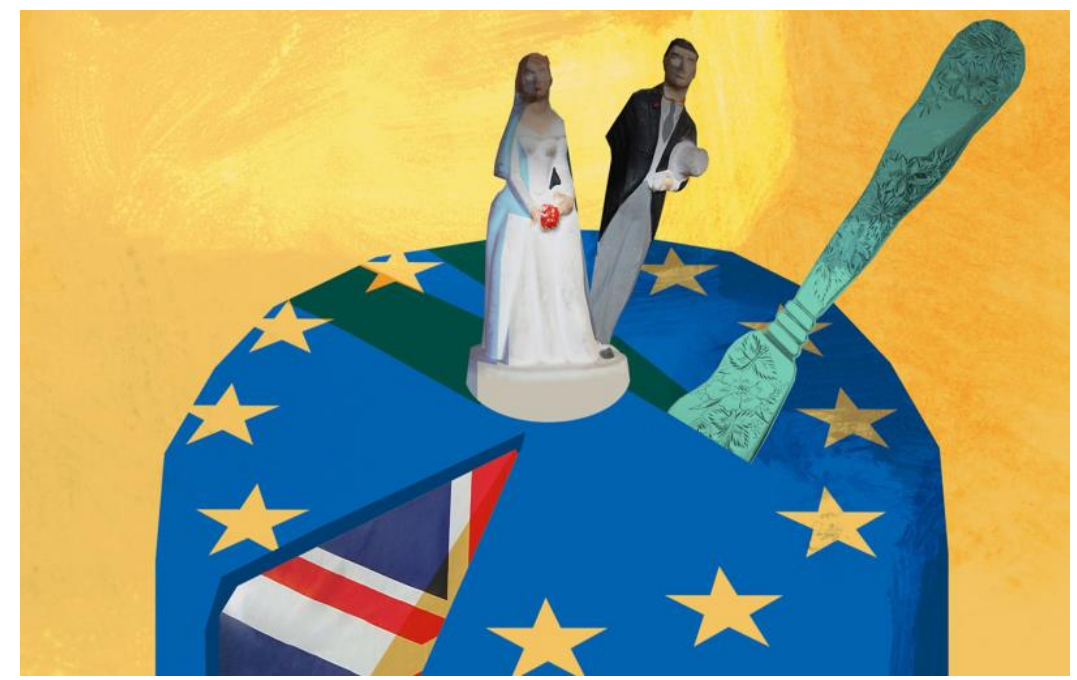

Figure 4. Image obtained by searching "Brexit; EU; Divorce" onto Google Images. Image downloaded from https://www.ft.com/content/7e0bce28-dbda-11e5-a72f-1e77444c66818 February 2018.

This image clearly is a visual and metaphorical depiction of Brexit. It served as an illustration for an online article entitled "What a British divorce from the EU would look like" released in the Financial Times.

This visual metaphor compares the process of Brexit to a divorce, giving the conceptual metaphor BREXIT IS A DIVORCE. It seems to be a relatively common way to conceptualise Brexit both verbally and visually as it is frequently encountered in the media and in political communication. However, Theresa May declared at the House of Commons in March 2017 that she did not like this metaphor and refused to 
use it because usually, when people divorce, they rarely stay in good terms, and that is something she wishes to avoid.

A second visual metaphor resulting or generated from the previous one can also be noted. The European Union and the United Kingdom seem to be represented as a married couple as illustrated by the two statues standing on what seems like a wedding cake. We can consider Britain as the bride since historically, Britain has often been personified as a female named Britannia who used to be featured on British coins and represented by a statute such as the statue of the Armada Memorial in Plymouth. In their research paper about the MARRIAGE metaphor in the context of Brexit, Tatjana Durovic and Nadezda Silaski also considered Britain as the "unfaithful wife" and the EU as the "aggrieved husband" (2017: 4). They also suggested that this metaphor is used frequently in discourse both to simplify and permit the understanding of the troubled relationship between the United Kingdom and the European Union (2017: 4).

Furthermore, the knife planted in the heart of the wedding cake decorated with the European flag can be seen as a metaphorical representation of Brexit as a stab in the back of the European Union, all the more so if we consider the male statue as the representation of the European Union since the knife puts it in the shade. What can be inferred from this visual metaphor is the fact that Brexit is perceived as an act of treason and it highlights the possible harm Brexit could cause to Britain and Europe. All in all, representing Brexit by a sharp object, whether a knife of a pair of scissors as in Figure 3 conveys a pejorative image of Brexit. The divorce metaphor also induces a change in the state of the relationship between Britain and Europe. 
The last picture I would like to analyse is the one I obtained by searching "Brexit; freedom" on Google Images.

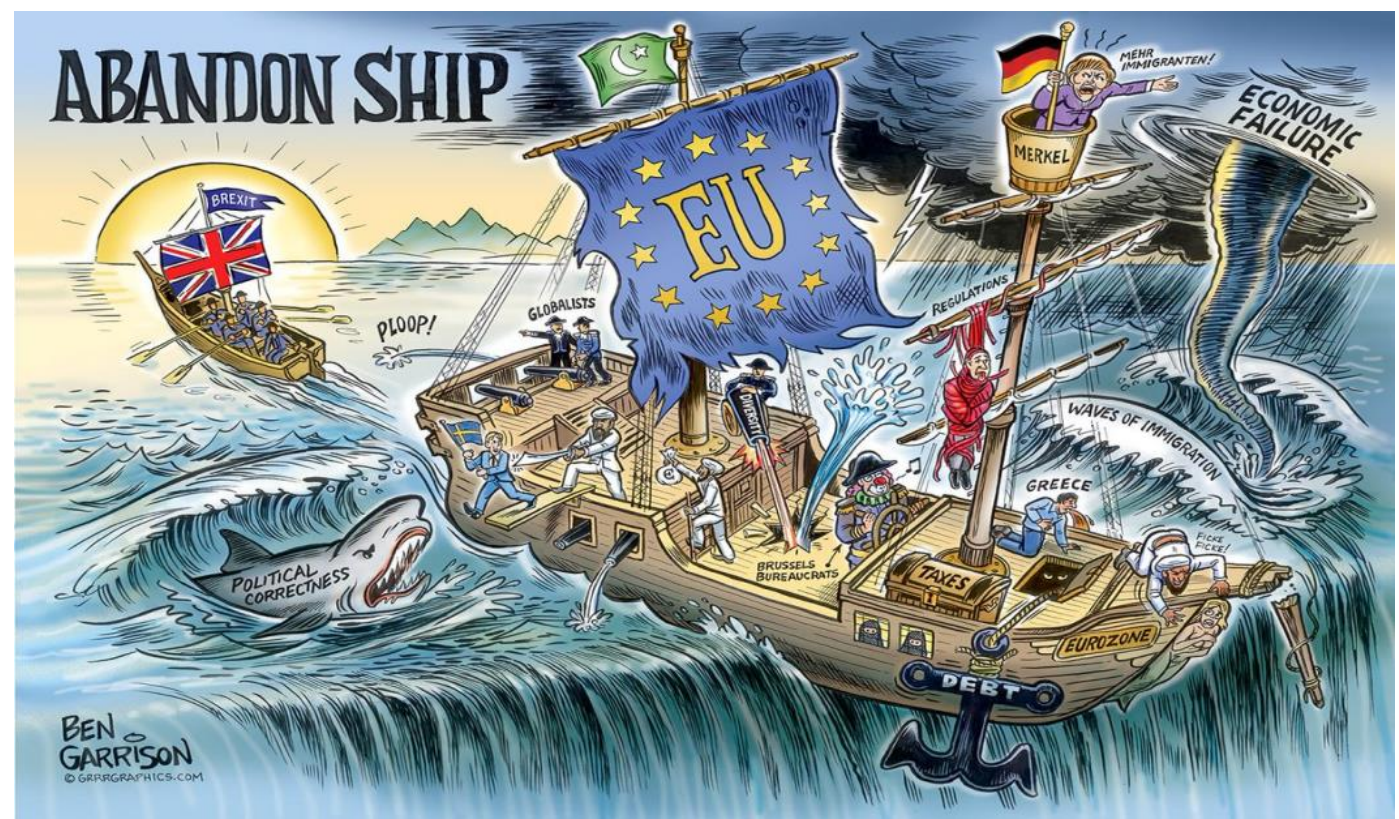

Figure 5. Image obtained by searching "Brexit, Freedom" on Google Images. Image downloaded from https://twitter.com/GrrrGraphics/status/746331297480507393/photo/1 in March 2018.

This image is a political cartoon made by cartoonist Ben Garrison and published on his twitter account the day following the referendum. It represents Brexit and the European Union via a combination of metaphors. Some of them are multimodal, others are monomodal.

The first metaphor that can be described is the one we already encountered in Figure 2, that is, the NATION AS A SHIP metaphor. Both the United Kingdom and the European Union are depicted as ships. The ship that stands for the United Kingdom is sailing in the opposite direction to the ship of the European Union. This element can be linked to the conceptual metaphor BREXIT IS A JOURNEY also present in Figure 1.

On top of that, a great number of multimodal metaphors are surrounding the ship of the European Union. For most of them, their target domains are expressed 
verbally whereas their source domains are visually depicted. For example, we can note the wave on the right standing for immigration, the clown leading the European boat representing Brussels bureaucrats and the big anchor at the front of the boat is compared to the debt and driving the boat down the cliff. There is also a reference to the conceptual metaphors UP IS GOOD and BAD IS DOWN since the boat of the EU is seen as going downwards and the British boat seems to be moving upwards, what is more, towards the light.

All these subtle multimodal metaphors are quite negatively connoted as regarded the European Union. As noted by Charles Forceville, political cartoons which portray state of affairs or well-known persons often invite us to map only negative connotations; it is a characteristic of the genre (2016: 13). On the contrary, it conveys a positive image of Brexit. It seems that for the cartoonist, by choosing to leave the European Union, Britain is now saved from sinking down with the EU. The fact that the British boat is moving towards the sun shows that Brexit is seen as a positive event. Thus, the cartoonist clearly expressed his point of view on the issue. As Olena Morozova wrote in her article: "both monomodal and multimodal metaphors of Brexit clearly express the stance of their creator and have considerable persuasive potential" (2017: 273).

To finish with, a parallel could be drawn with Plato's allegory of the Ship of Fools in Book VI of Republic which also describes the nation as a ship. This allegory could indeed be linked to the ship representing the European Union.

To sum it up, the analysis of these visual representations of Brexit show that visual metaphors are often combined with metonymies as it is the case in most images studied. Visual metaphors seem to have a strong persuasive power as they 
depict explicitly the reality in a positive or negative way. For instance, Figure 5 caricatures Europe in such a negative way that when looking at this image, only the negative aspects of the European Union stuck to our mind, which can lead us to believe that Europe is bad and Brexit is good.

As for the representation of Brexit in these images, Figure 1 gives us a quite neutral representation of Brexit, probably because the BBC is a national service and it is supposed to be neutral. In contrast, Figures 3, 4 and 5 are slightly more connoted. Figures 3 and 4 render a derogatory image of Brexit by comparing it to sharp objects cutting the links between the United Kingdom and the EU or stabbing the EU. Whereas Figure 5 presents Brexit as the right path to follow in order to escape from the inevitable sinking that the European Union is risking. The source domains that conceptualise Brexit in this part of my corpus are the domains of DIVORCE, JOURNEY, CRUISE, (SHARP) OBJECT, which can be illustrated by the following graph:

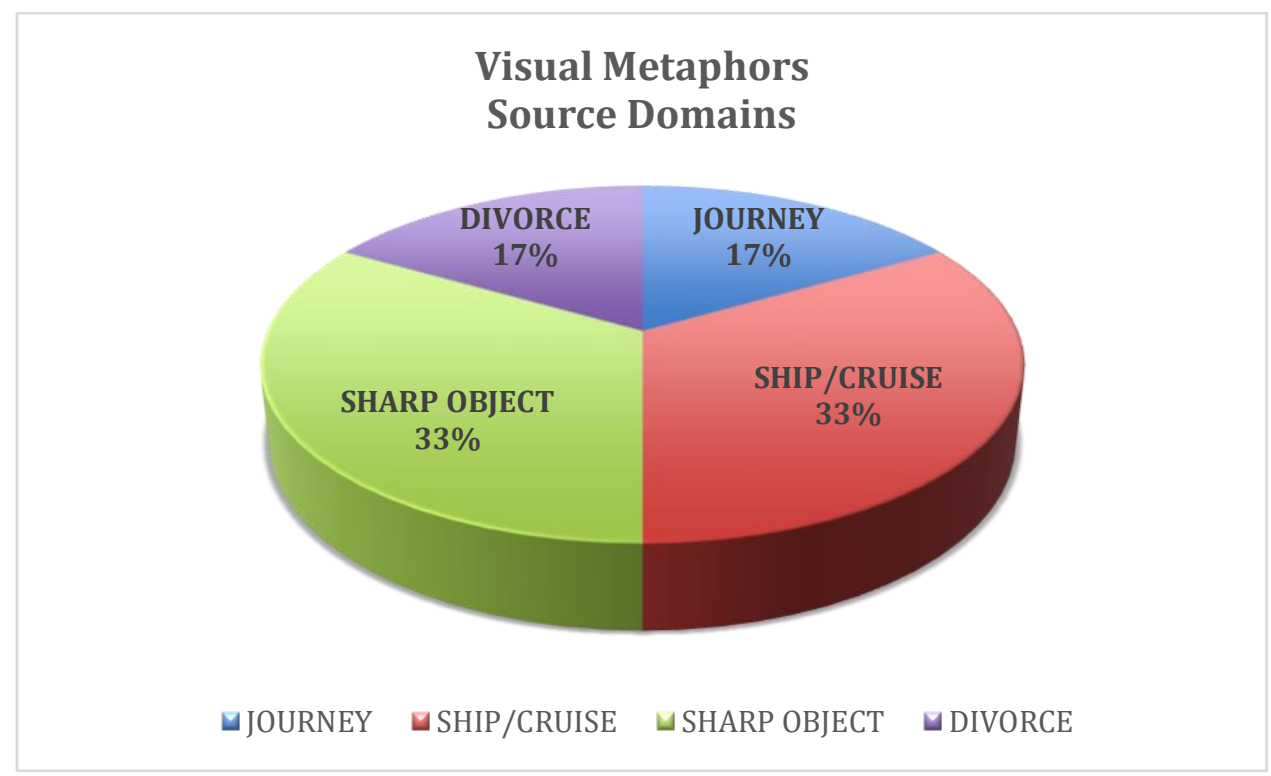


Although analysing solely five pictures might not be sufficient to make general assumptions and to be able to give a proper conclusion, we can still come up with a global tendency. The study of this part of my corpus shows that the domain linked to everything that has to do with the sea and ships is a popular way to conceptualise Brexit in visual contents. This is probably due to the fact that it is an easy way to represent this event, it allows us to get a concrete mental picture for this abstract entity, and the NATION AS A SHIP metaphor has been frequently used in politics, at least ever since Plato's Re 


\subsection{Corpus Analysis: Verbal Metaphors}

Let us move on to the following part of this thesis by analysing conceptual metaphors in the speeches I selected for my corpus. I will first discuss each speech separately and then give a general tendency. For each speech, I will give an account of the main conceptual metaphors and provide a few examples of metaphorical expressions for each conceptual metaphor mentioned. The terms that are in bold fonts correspond to the terms that are used metaphorically. I will illustrate my results with graphs showing the percentage of use for each source domain.

\subsubsection{Written Documents}

\section{Conservative Manifesto 2015}

To begin with, let us have a look at the Brexit metaphors used in the last two Conservative Manifestoes for the General Elections of 2015 and 2017.

For the Conservative Manifesto dating from 2015, which was supporting David Cameron as Prime Minister, the topic of Brexit holds quite an important place since the EU referendum was Cameron's main campaign promise. In fact, four pages of the Manifesto are dedicated to this topic. Among these four pages, twelve linguistic metaphors can be noted. Most metaphors in this document tend to conceptualise Brexit in terms of a JOURNEY. We can find expressions such as "we do not want to stand in the way", "help Britain move ahead", "be driven by a determination." The second most prolific source domain is the one that is used to talk about Brexit and the European Union as an obstacle, something that has to be crossed. The Conservatives express their desire to "break down the remaining barriers" for instance. 


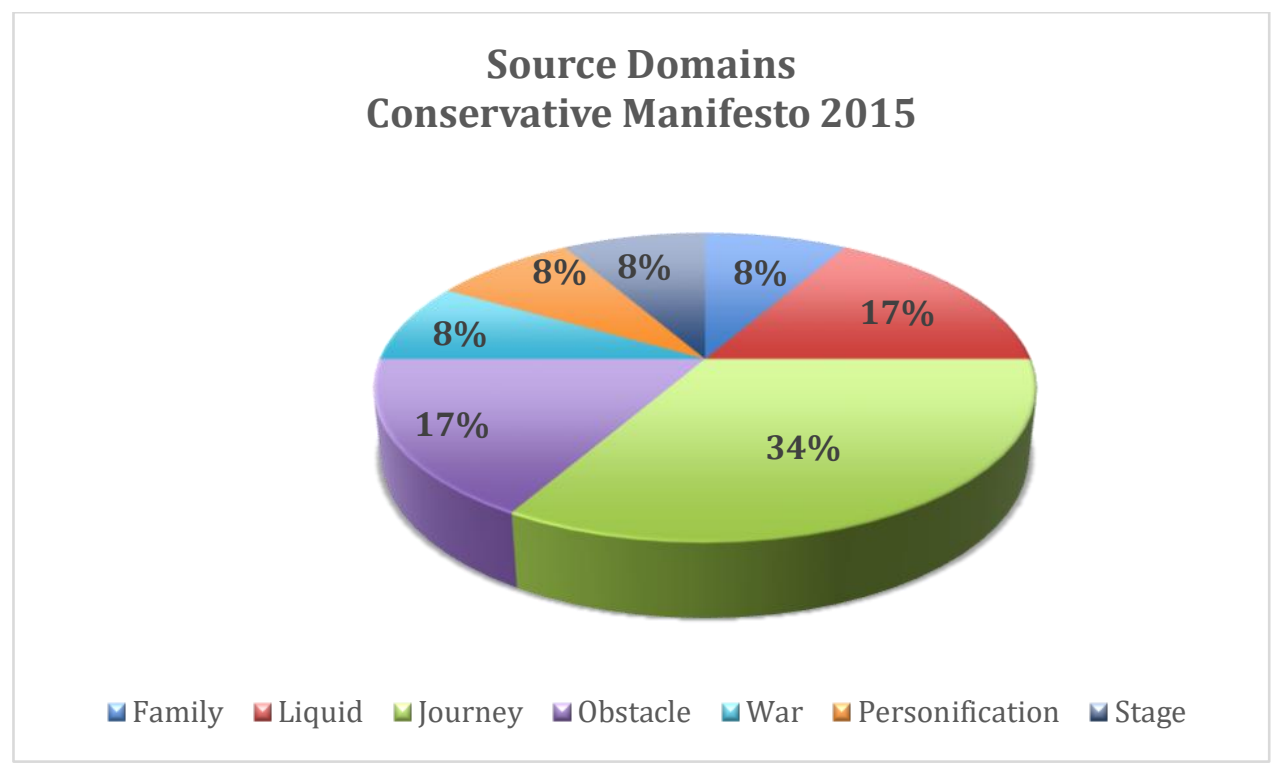

\section{Conservative Manifesto 2017}

The Conservative Manifesto from 2017 supporting the election of Theresa May is even more focused on Brexit. This is probably due to the fact that the General Election of 2017 aimed to elect a new strong and stable leader that will be in charge of leading Brexit negotiations with the European Union. As can be seen in the graphic hereunder, the most recurring source domain to talk about Brexit in this document is the domain of WAR. The other countries of the European Union are described on many occasions as "allies", which is usually a term that belongs to the domain of WAR. The expression "ideological crusade" can also be encountered on page 9 of the Manifesto. I have decided to put the term crusade under the concept of WAR since it shares similar characteristics and in the context, it could be replaced by the words battle or war and it will still convey the same idea.

The second most prolific source domain is the domain that includes the idea of SAILING and SHIPS. On page 12 for instance, we can read the expression "to emerge from Brexit a strong and united nation" and on page 32 we find "the UK is embarking upon another era." As we have seen in the analysis of the visual 
elements of the corpus, conceptualising Britain as a SHIP and Brexit as a CRUISE is quite frequent. We can also mention that in this document, the Conservatives liked to consider other European countries as friends. They wrote: "we want to remain committed partners to our friends across the continent." They consider their relation with the continent as a friendship. They also used the concept of JOURNEY to describe Brexit: "We need to deliver a smooth and orderly departure from the EU."

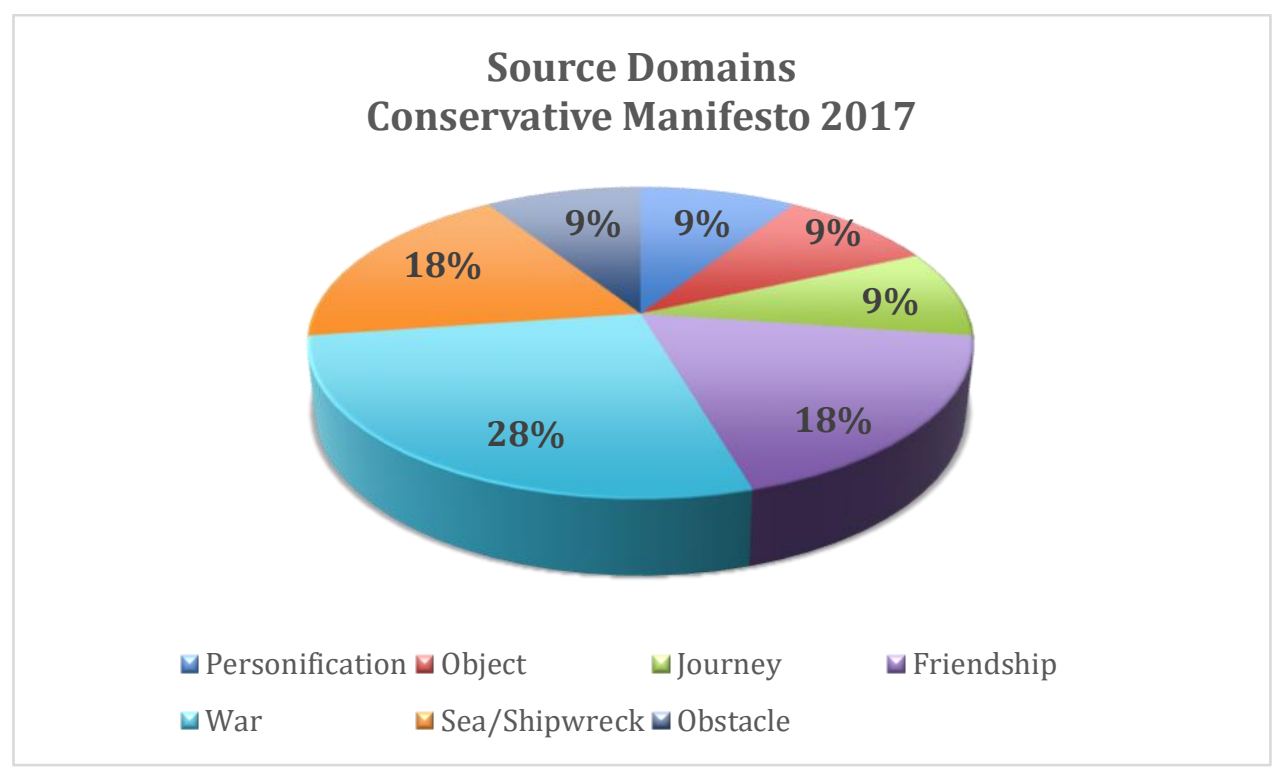

\section{Theresa May's letter to Donald Tusk triggering Article 50}

What is the most striking about this letter is the importance given to the relationship between the United Kingdom and the European Union. Theresa May stresses the fact that she wants her nation to remain friends with the European Union, despite Brexit. That probably explains why she mostly used metaphors with the source domain of FRIENDSHIP to talk about the EU-UK relationship. She wrote: "we want to remain committed partners to our friends." She described the European Union as the UK's "closest friend." Besides, she also used the concept of 
OBSTACLE when talking about Brexit as in the following occurrence: "In order to avoid any cliff-edge as we move from our current relationship to our future partnership." What is also interesting in this quote is the shift from relationship to partnership; it implies that Brexit will lead to a change in the state of the relations that unite the United Kingdom and the European Union, as is the case during a proper divorce.

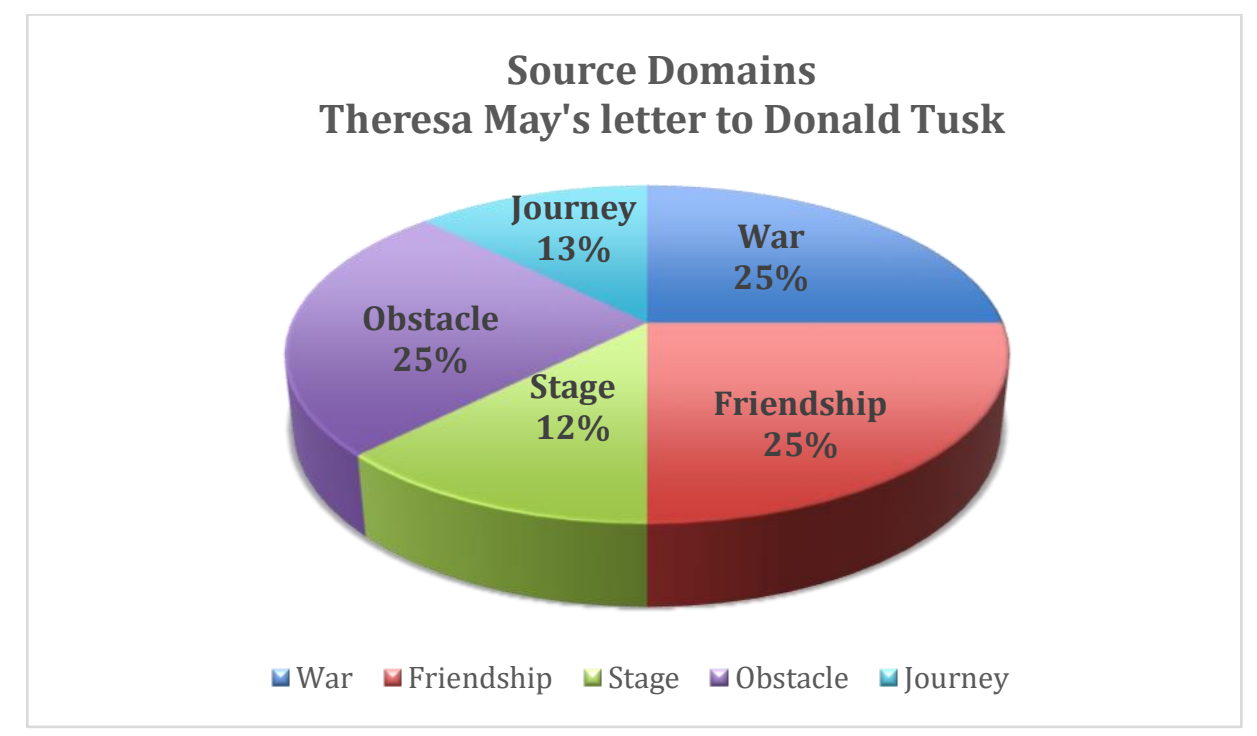

\subsubsection{Speeches}

\section{Speech by David Cameron at Bloomberg Institute, 23 January 2013}

During this speech, David Cameron used a large variety of metaphors with different source domains. I noted no fewer than twenty-four metaphors related to Brexit in his speech. He used the source domain of RACE on four occasions, race referring here to a speed contest. For instance, he declared: "a new global race of nations is underway today". It leads us to believe that he conceptualised the European nations as being in a race, which highlights the competitive atmosphere 
that dominates in Brussels. Although the RACE metaphor is used a lot by David Cameron, we scarcely encounter this metaphor anywhere else so we cannot say that Brexit is conceptualised in terms of a RACE generally speaking. However, we could connect it to the JOURNEY metaphor which he also made reference to on several occasions. He claimed: "people feel that the EU is heading in a direction that they never signed up to", "the British people have set themselves on a path to an inevitable exit", "the EU would be greatly diminished by Britain's departure".

Another interesting metaphor that he insisted upon consisted in comparing the European Union to a family. For instance, he said: "the UK is sometimes seen as a rather strong-minded member of the family of European nations". I decided to classify this metaphor under the concept of FAMILY, but it can also be considered as a personification as it gives the UK some human characteristics, especially with the use of the adjective strong-minded whose scope is on the UK. Personification can be seen as a type of metaphor involving our experience of human beings as source domain (Lakoff and Johnson 1980: 33). Elena Semino claimed that personification in political discourse is a way to simplify both the reader's and the writer's task and it presents abstract and complex notions in terms of human activities (2008: 103). 


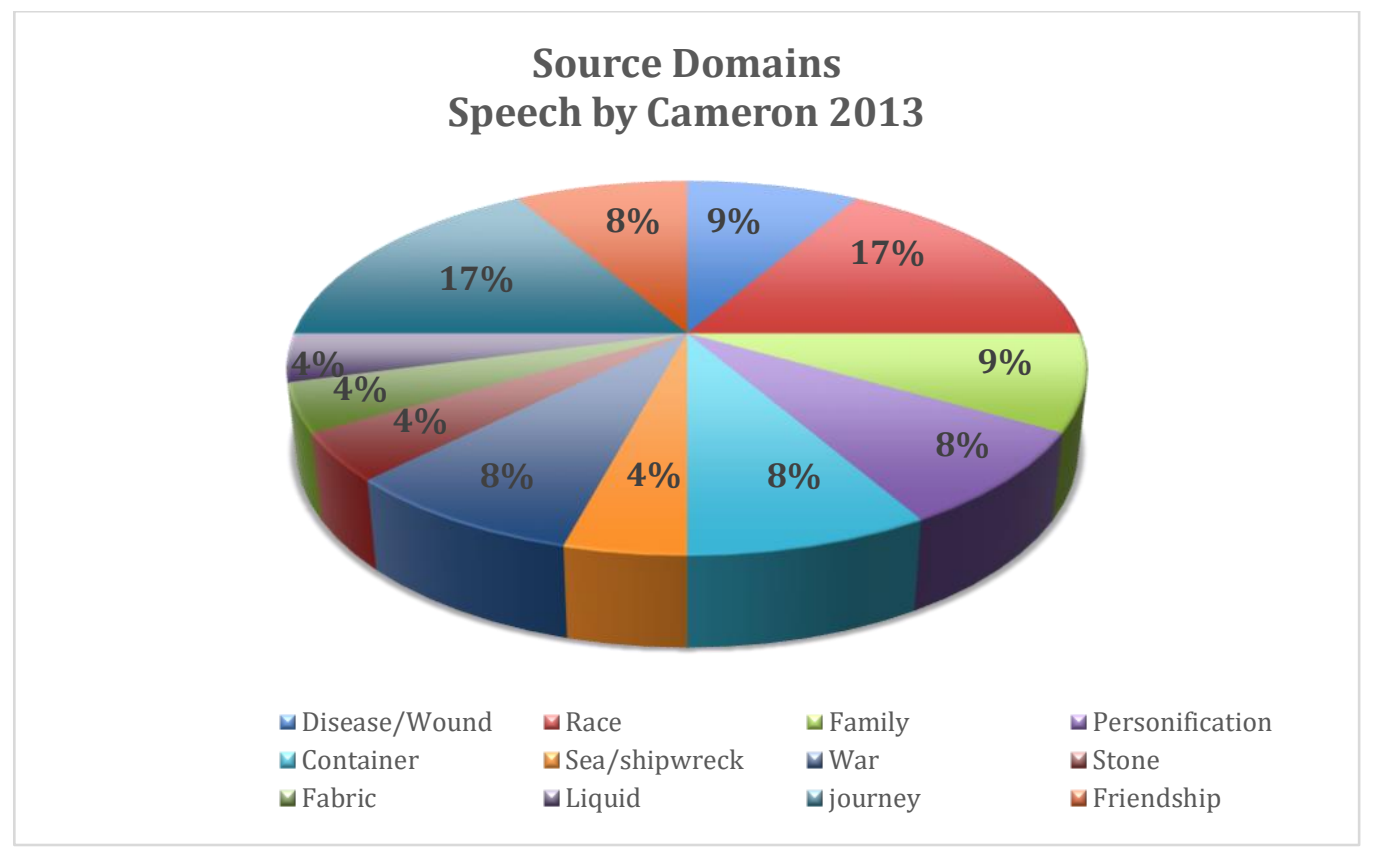

Boris Johnson EU Referendum Vote Leave Speech, 16 May 2016

Boris Johnson's speech was a bit tricky to analyse in terms of conceptual metaphors as he mostly used vivid metaphors, that is, metaphors that he coined especially on the occasion of that specific speech and that are unlikely to be encountered in any other context. So as to understand the results obtained for the analysis of this speech, it is thus necessary to take into account the context. He gave this speech during the campaign, just before the referendum while he was visiting David Nieper factory in the North of England. It is a factory specialised in the designing and manufacturing of fashion undergarments. It seems that he adapted his speech to his audience, and he used an extended metaphor based on the source domain of undergarment to talk about the European Union and Brexit. Here are some examples of his feats of rhetoric: "when you look at the EU now, it makes me think of some badly designed undergarment that has now become far too tight in some places and dangerously loose in other places", "I say their ${ }^{9}$ pants are on

\footnotetext{
${ }^{9}$ He was referring to the Remain Campaign.
} 
fire, they want a new pair", "Knickers to the pessimists! Knickers to all those who talk Britain down!". But apart from all these incongruous pants-related metaphors, Johnson also used more common source domains such as the domain of JOURNEY: "It [the EU] is moving completely in the wrong direction."

He also conceptualised the European Union as a container when he said "the thing that we are in now, the EU." Finally, he compared Brexit to an act of Independence, as if the campaign for Brexit was a war of Independence against the EU, which provides a relatively negative image of the EU.

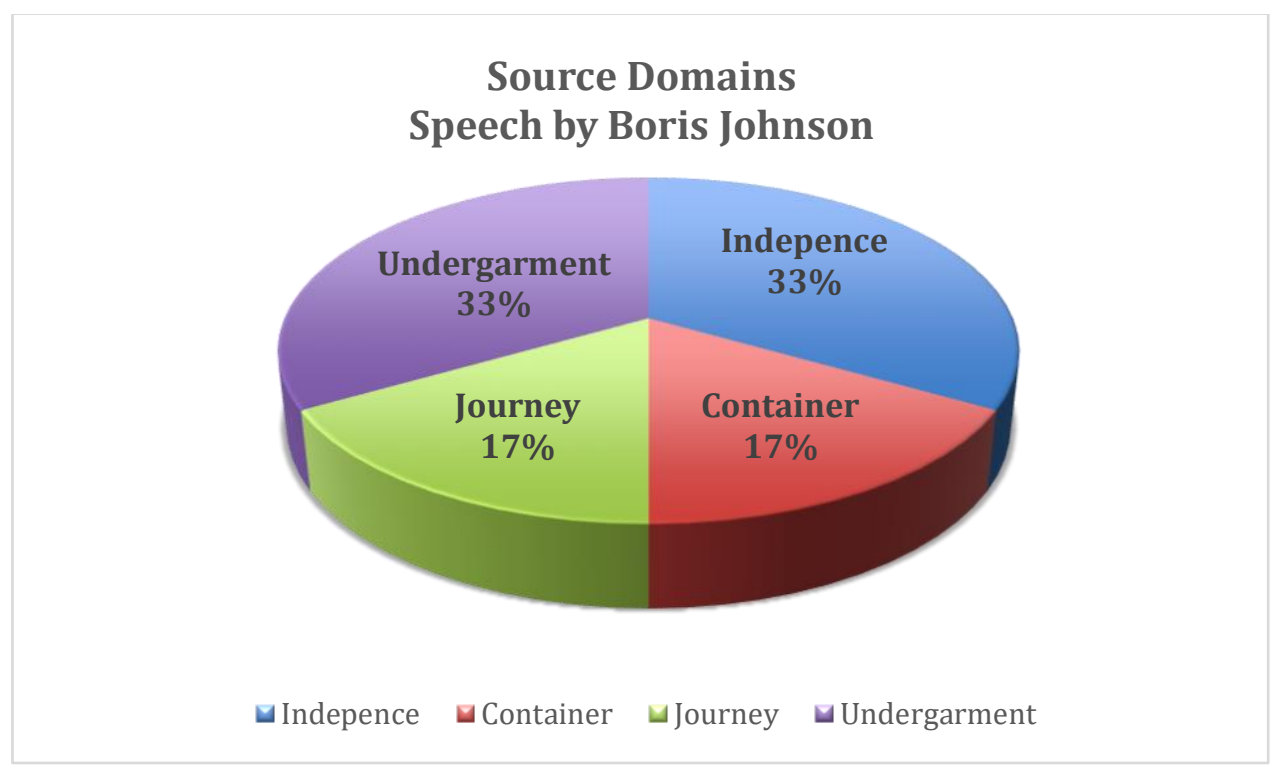

\section{Speech by Theresa May, Lancaster House, 17 January 2017}

This speech was a milestone in the course of Brexit since it is in that speech that Theresa May set out the Government's plan for Britain and the priorities the Government will focus on during the Brexit negotiations. All along this speech, Theresa May kept referring to the European countries as the UK's friends. Among the thirty-eight metaphors related to Brexit in this speech, eleven of them are built 
upon the concept of FRIENDSHIP. Here are a few examples of metaphorical expressions that I grouped under this concept: "I want us to be the best friend and neighbour to our European partners", "A country that reaches out to old friends", "Britain wants to remain a good friend to Europe." As I mentioned in my analysis of David Cameron's speech, these metaphors involving the concept of FRIENDSHIP could also be considered as a personification since countries are given human characteristics. Friendship is a faculty that normally solely concerns human beings. Another source domain that is encountered a lot in his speech is the domain of WAR. In addition to calling European countries friends, Theresa May also chose the term allies to refer to them, which is usually a term that belongs to the lexical field of war. So the source domain of WAR is also represented. She stated that Brexit was not "an attempt to do harm to the EU", which can also be considered as a metaphor with WAR as its source domain.

The concept of JOURNEY is also present on some occasions, as in almost every speech. She conceptualised Brexit as a path: "there are some voices calling for a punitive deal that discourages other countries from taking the same path." There is a common element with the letter she wrote to Donald Tusk: she also mentioned the fact that Brexit will lead to a shift in the relationship between the United Kingdom and the European Union. She claimed: "we change our existing relationship to a new partnership with the EU." 


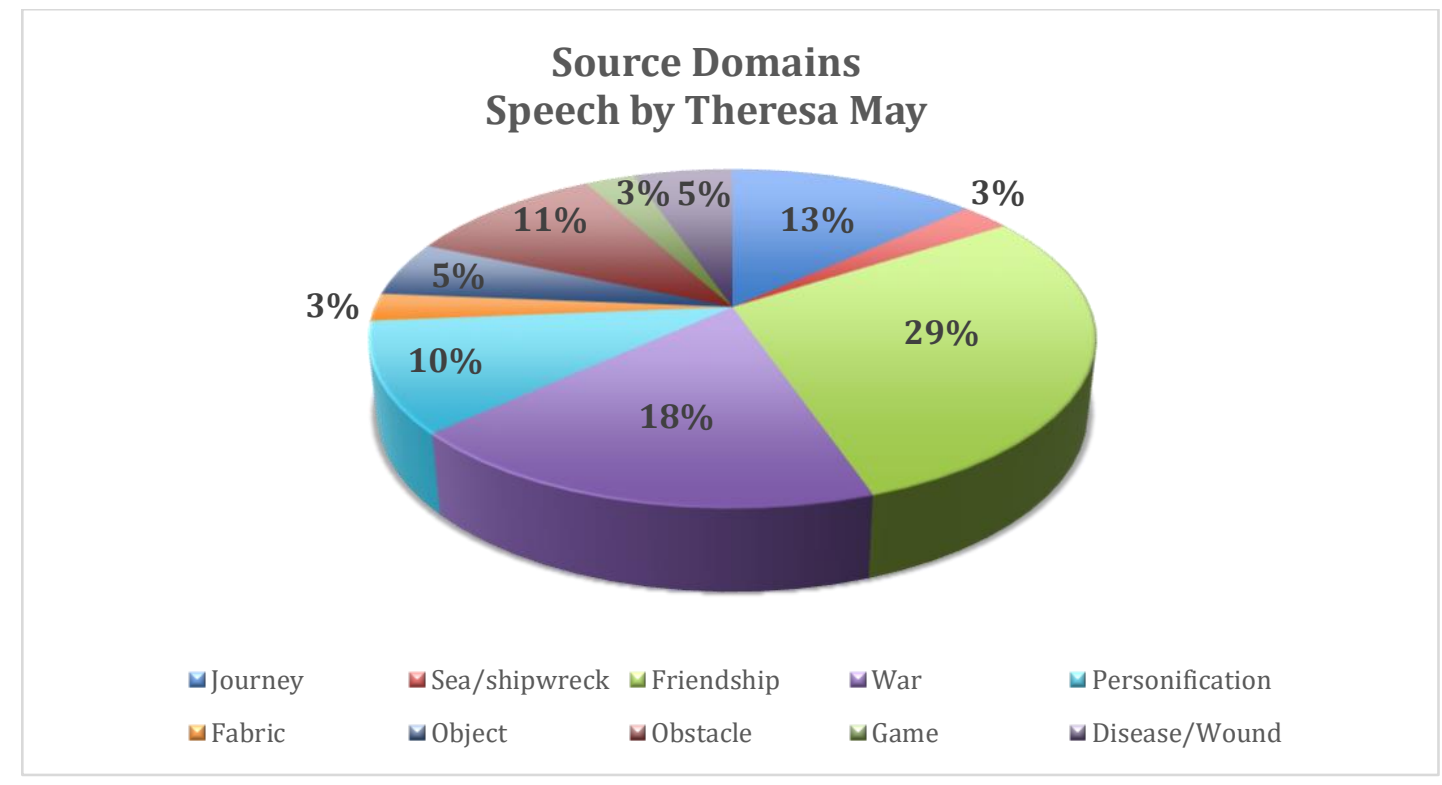

Speech by Nicola Sturgeon on Brexit at the David Hume Institute, 16 January 2018

The aim of this speech was to establish the Scottish Government's position regarding the EU Withdrawal Bill ${ }^{10}$. Nicola Sturgeon made the most of this speech to express her point of view on Brexit, and we are not without knowing that she strongly disapproves of it as her country voted to remain by $62 \%$ but still they are forced to leave the EU. This probably explains why the concept of WAR is so strikingly preponderant in her speech. She claimed that: "all forms of Brexit are likely to harm the economy." She thinks that "harder Brexit will cause greater damage." She argues twice about the "economic harms of Brexit." In short, Brexit is clearly seen as something harmful and negative in the eyes of the Scottish Prime Minister. Besides, Nicola Sturgeon used expressions showing that she conceptualised Brexit as an object, especially when she talked about soft and hard Brexit. In her article, Olena Morozova also classified these linguistic expressions

\footnotetext{
${ }^{10}$ Bill passed in the UK Parliament in July 2017. Its aim is to make sure the EU law does not apply to the UK anymore after Brexit and converts almost all EU laws into UK laws.
} 
under the conceptual metaphor BREXIT IS AN OBJECT. She explained that the terms hard and soft Brexit refer to the extent to which the UK and the EU are ready to compromise (2017: 268). The phrase soft Brexit can also be linked to the idea of soft power coined by Nye in 2005, and which supposedly denotes a strategy in foreign international relations and refers to "the ability of a country to persuade other countries to do what it wants" (Morozova 2017: 255). Moreover, according to the BBC's guide to Brexit jargon, the phrase hard Brexit "is often used by critics of Brexit who think it will harm the UK economy."

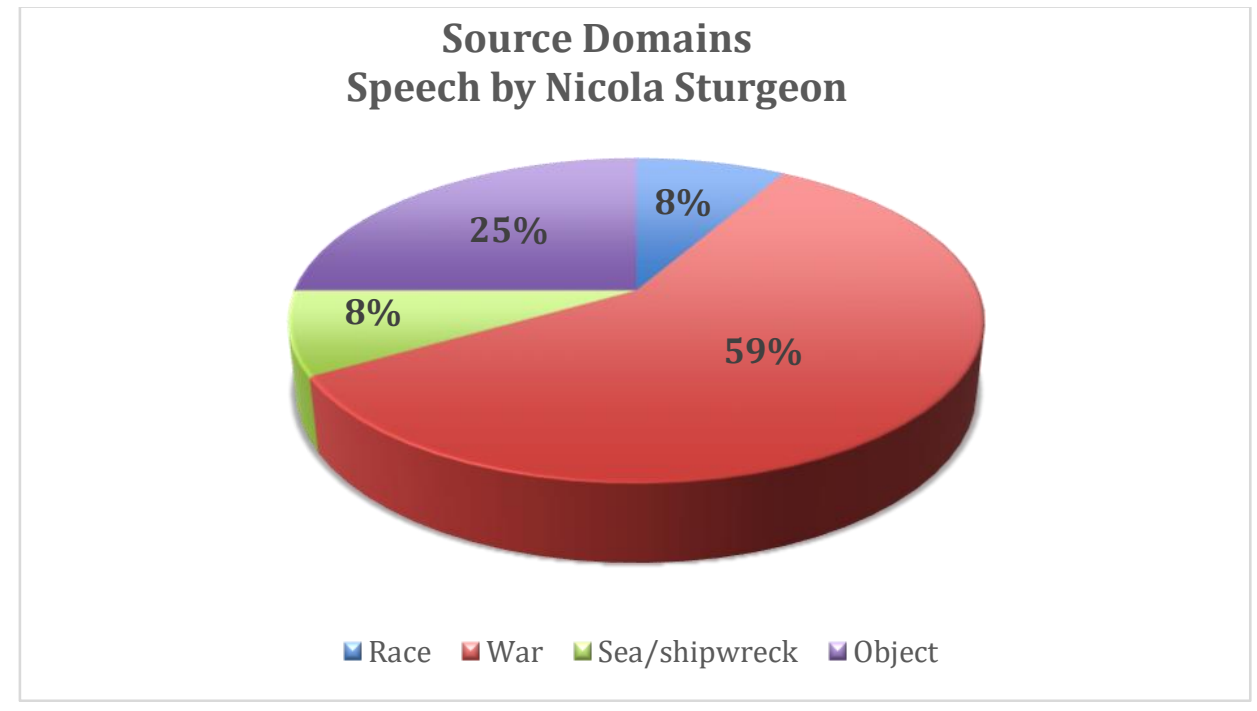

2017

\section{Speech by Jeremy Corbyn at the Labour Party Conference, September}

Although Brexit is mostly talked about in Britain by the Conservative Party, it is important to take into consideration the point of view of the main opposition party, that is, the Labour Party, with Jeremy Corbyn at its head. As we know, the Labour Party was part of the Remain campaign. They strongly believed that the future of the United Kingdom should be within the European Union. Jeremy 
Corbyn's speech lasted for seventy-five minutes and tackled the main issues regarding the UK politics at the moment, including Brexit but it was not a speech entirely devoted to it. Out of seven metaphorical expressions related to Brexit identified in his speech, four of them are built upon the source domain of JOURNEY. For instance, he used the expression "a shambolic Tory Brexit driving down standards", he argued about "a new common sense about the direction Britain should take" and he said that the results of the referendum should not mean "giving a green light to a reckless Tory Brexit agenda", green light being a reference to the traffic lights. Moreover, Jeremy Corbyn represented Brexit as an obstacle a couple of times. Just like Theresa May, he employed the expression cliff-edge Brexit: "A cliffedge Brexit is at risk of becoming a reality." He also suggested that the country should be united for "a future beyond Brexit." According to the online etymological dictionary etymonline.com, beyond means "on the other side." Thus, in this sentence, Jeremy Corbyn conceptualises Brexit as an obstacle that has to be overcome.

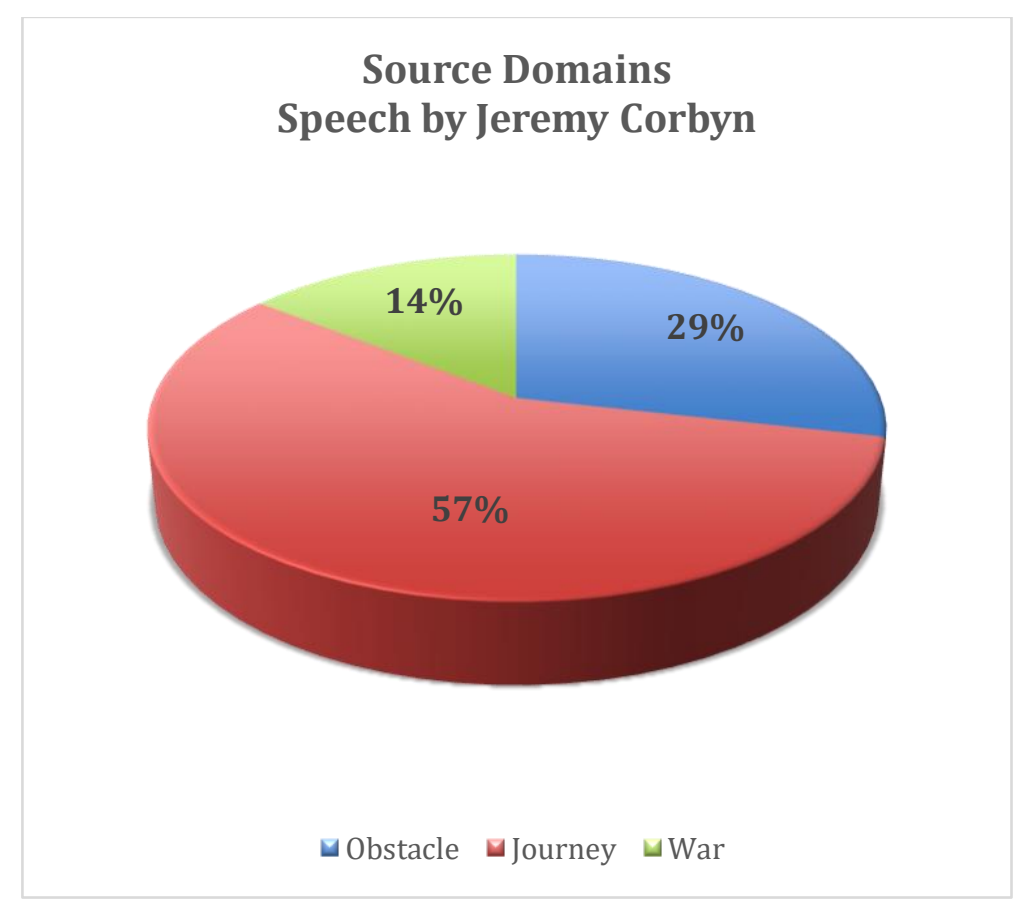




\section{Plenary Session on Brexit, EU Parliament, April 2017}

I have decided to analyse some selected interventions made by representative political figures at the European Parliament. My focus will be on Guy Verhofstadt and Jean Claude Juncker as it is interesting to take into account the points of view of two tenors of the European Parliament who strongly supported the Remain campaign and profoundly believing in the future of the European Union.

First, Guy Verhofstadt used an interesting extended metaphor comparing the relationship between the European Union and the United Kingdom with a married couple. He said: "the relationship between Britain and Europe was never a love affair and not a question of wild passion but rather a marriage of convenience". He then added: "let us be honest about this; it was only a short honeymoon". In other words, Guy Verhofstadt adopted the MARRIAGE metaphor as seen in Figure 4. However, he nuanced it by declaring that it was marriage by convenience, and not by mutual love, which slightly changes the connotation of the metaphor. It is certainly a more realistic metaphor when considering the history of Britain and Europe as illustrated on of the previous parts dealing with the context. Furthermore, the MARRIAGE metaphor presupposes and is linked to the BREXIT IS A DIVORCE conceptual metaphor. We can also mention his vivid metaphor describing Brexit as a catfight: "and a young generation that will see Brexit for what it really is: a catfight in the Conservative party that got out of hand". It is quite an unusual way to talk about Brexit so it is difficult to find a conceptual metaphor that could encompass this expression. The most logical interpretation would be to consider it as part of the WAR conceptual metaphor.

As for Jean Claude Juncker, he used the domain of WAR to talk about the Brexit negotiations as well. When talking about the Brexit deal, he said: "no deal 
means no winners; everybody will lose". The use of these terms in bold can be interpreted as metaphors comparing the reaching of a deal to the winning or losing of a battle, so it can be classified under the conceptual metaphor BREXIT IS A WAR. He also referred to the source domain of MARRIAGE to describe the relationship between the EU and the UK and Brexit on a couple of occasions: "we have dissolved our vows of marriage" and "our divorce lawyers will now look into the details". The latter expression also refers to the metaphor BREXIT IS A DIVORCE.

Last but not least, Nigel Farage made a brief but interesting statement about Brexit. Much like Boris Johnson, Farage mainly used vivid metaphors in his speech, hence the difficulty to classify them in terms of conceptual domains. He began his statement by comparing the time it took to Theresa May to write the letter triggering Article 50 to gestation: "it may have taken nine months, a pretty full gestation". This statement is indeed metaphorical. However, we cannot really say that it is a way to conceptualise anything. Then, he used a controversial extended metaphor comparing the European Union to a mafia, which led to outrageous reactions from the members of the Parliament, especially from the Italian President of the European Parliament. He claimed that the Brexit bill was a sort of ransom: "we have to pay a bill that has clearly been plucked out of the air, which is a form of ransom demand"; "that is how we are being treated, we are being given a ransom note". He continued: "you're behaving like the mafia; you think we are hostage". The first half of this utterance cannot be taken into account for our analysis as it is not a metaphor but a simile as we can see by the use of the comparative tool like. Another metaphor that could be linked to these last few ones is the following: "it is like saying you can't get yourself a dwelling when you leave prison". 
Apart from the one slightly out of the blue using the source domain of gestation, most of the metaphors used by Nigel Farage indicate that he conceptualises the European Union as a prison, as a place where the United Kingdom is constrained and deprived from its liberty, which conveys a deeply pejorative image of the Union but is totally in line with his ideology. For practical reasons, I decided to make only one graph which encompasses all the metaphorical expressions of both European leaders, Guy Verhofstadt and Jean Claude Juncker, as they used similar source domains and their opinions seem to be converging.

All things considered, I have identified as many as twenty-one source domains in the entire corpus; all of them are mentioned in the chart that follows:

\begin{tabular}{|c|r|}
\hline Source Domains & Occurrences \\
\hline War & 28 \\
\hline Journey & 20 \\
\hline Friendship & 19 \\
\hline Obstacle & 10 \\
\hline Personification & 7 \\
\hline Object & 6 \\
\hline Wedding & 6 \\
\hline Container & 5 \\
\hline Sea/shipwreck & 4 \\
\hline Race & 4 \\
\hline Disease & 4 \\
\hline Family & 3 \\
\hline Liquid & 3 \\
\hline Fabric & 3 \\
\hline Undergarment & 3 \\
\hline Independence & 3 \\
\hline Stage & 2 \\
\hline Prison & 2 \\
\hline Stone & 1 \\
\hline Game & 1 \\
\hline Pregnancy & 135 \\
\hline
\end{tabular}

Table 1. Metaphors by Source Domains 
The conclusion that can be drawn from this analysis is that according to the statistics obtained, in the verbal data, most of the metaphors used by the politicians are built from the source domain of WAR (21\%). It is closely followed by the source domain related to JOURNEY (15\%) and FRIENDSHIP (14\%). The fact that these domains are recurrent in almost every speech analysed above allows us to come to the conclusion that Brexit is mostly conceptualised in terms of WAR, JOURNEY and FRIENDSHIP.

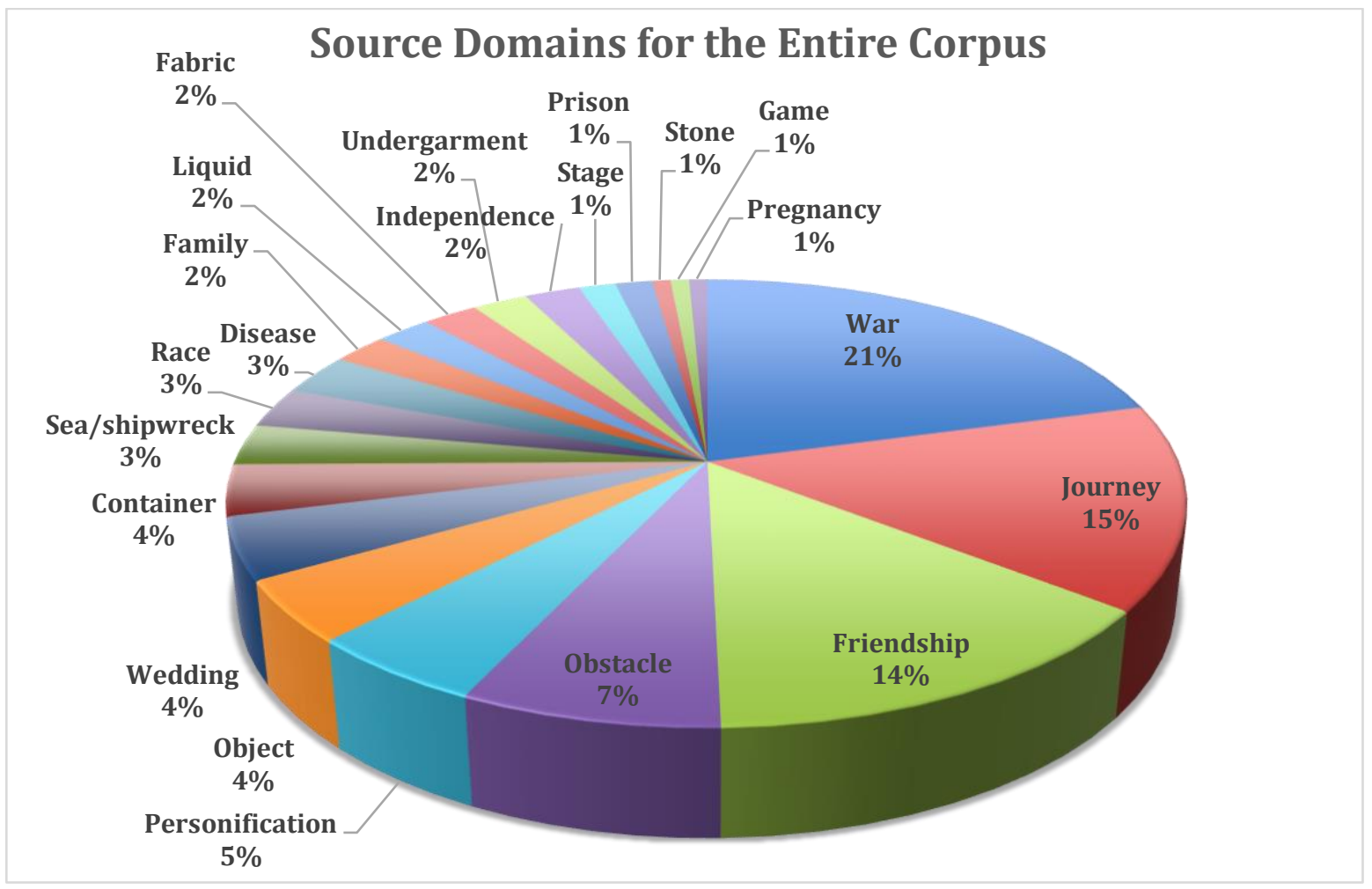

This graph illustrates the data collected in the chart. It allows us to visualise more clearly the proportions of metaphorical expressions for each source domain. 


\subsection{Metaphorical Scenarios in Brexit Discourse}

Following this corpus analysis, it is now interesting to look a bit closer at the results obtained. Each of the three most recurrent conceptual metaphors seem to be forming metaphorical scenarios. According to Andreas Musolff, a conceptual metaphor is said to be forming a scenario when metaphoric expressions are recurrent across a corpus (2006: 28), which is indeed the case for our three metaphors. Musolff also raised another interesting point on that issue. He claimed that metaphorical scenarios "help to shape the course of public debates and conceptualisations of politician target topics" (2006: 28). Therefore, we can assume that politicians tend to shape the topic of Brexit in debates and in people's minds through the domains of WAR, JOURNEY and FRIENDSHIP. This part will provide a more detailed interpretation of these three conceptual metaphors.

\subsubsection{BREXIT IS A JOURNEY}

The JOURNEY metaphor seems to be rather common in political communication, especially from the leaders of English-speaking countries as demonstrated by Jonathan Charteris-Black in his corpus analysis of speeches by Tony Blair, Winston Churchill, Margaret Thatcher (2005: 200). This might be due to the fact that JOURNEY is a concept that is easily identifiable and experienced by most human beings; it is easy for us to have a mental representation of this type of experience. From a literal point of view, a journey involves some kind of physical movement, a displacement from a starting point to an end point. Charteris-Black postulated that the starting point was usually in the present and is often familiar 
whereas the end point is generally in the future and unknown yet (2005: 199). According to him, JOURNEY metaphors "imply some type of planned progress and are inherently purposeful" (2005: 199). As a consequence, by using this type of metaphor, politicians may want to imply that they have a clear idea of where they would like to be in a more or less near future and where they want to drive their countries to. This is particularly relevant when looking at certain metaphorical expressions such as the ones used by Theresa May in her speech at Lancaster House where she stated that her plans for Brexit will "lead toward a brighter future" or when she claimed: "we will follow a better path".

The BREXIT IS A JOURNEY metaphor can be seen as stemming from the LIFE IS A JOURNEY metaphor. In their guide to poetic metaphor, Lakoff and Turner tried to find out the origins of the JOURNEY metaphor. According to them, this metaphor would find its roots in the Bible with the conception of God as a guide who helps his believers to choose the right path over the evil one (1989: 10). This idea of good and bad path is an element that also applies to some metaphors encountered in the corpus depending on their cotext and context. For instance, Boris Johnson mentioned that the EU was "moving completely in the wrong direction". The association of the noun direction used metaphorically with the adjective wrong can be connected to this idea of a potential evil path. The same argument applies to Jeremy Corbyn's following statement: "a shambolic Tory ${ }^{11}$ Brexit driving down standards". We can even consider this metaphor as also being part of the conceptual metaphor DOWN IS BAD (as opposed to GOOD IS UP). This suggests that, in Corbyn's opinion, Brexit associated with the Conservative Party would lead standards, and more generally Britain on the wrong path.

\footnotetext{
${ }^{11}$ Colloquial way to designate the Conservative Party.
} 
Besides, following the origins of this metaphor as described by Lakoff and Turner, by using this conceptual metaphor, politicians are able to put themselves in a position of a guide (Charteris-Black 2005: 41). They try to convince the voters that following their ideologies will lead them to the right path.

\subsubsection{BREXIT IS A WAR}

The BREXIT IS A WAR metaphor shares similar characteristics with the JOURNEY metaphor. This metaphor is also frequently encountered in a political context, especially in times of elections. This is due to the fact that politics shares common features with actions perpetrated in times of war, except that instead of fighting physically with actual weapons, politicians fight with words. Lakoff and Johnson argued that the WAR metaphor in argument and politics allowed us to conceptualise what a rational argument is thanks to something that is easier for us to understand, namely, physical conflict (1980: 62). Elena Semino argued that metaphors from the source domain of WAR are generally used in relation to conflict between individuals, political parties, governments (2008: 100). Political crisis and decisive moments tend to be conceptualised in terms of war, and such is also the case for Brexit. It is the most frequent source domain (21\%). The question is, why so? Why do politicians like to compare themselves to fighters?

One of the first reasons is that it further accentuates the difference, the opposition between two parties (Cammaerts 2012: 14). In the case of my research, this aspect of the WAR metaphor is used in two ways. It seems that the politicians, especially the Conservatives who were rather doubtful about the European Union, tended to use this metaphor primarily to accentuate the difference between the 
United Kingdom and the European Union. For instance, in their 2015 manifesto, the Conservatives expressed their desire to "resist EU attempts to restrict legitimate financial service activities". Additionally, Nigel Farage and Boris Johnson both likened the day of the referendum to an "Independence Day". This also refers to the WAR metaphor, to that same idea of gap between the UK and the EU and joins in the building of an adversarial relationship (Flusberg et al. 2018: 12). That is what politicians insist on when using such metaphors.

In contrast, the WAR metaphor can also be used for quite different purposes. Something particularly striking in the corpus is the recurrence of the word allies to designate other European countries. This word can indeed be seen as being used metaphorically since it first refers to a union of countries fighting together during the two World Wars. It appears a dozen times across the whole corpus. It is even more striking in Theresa May's speech at Lancaster House where she used the term every time she talks about Europe. In that case, it seems that the WAR does not convey the same image. Theresa May may be using it a lot so as to strengthen the fact that she wishes the United Kingdom and the European Union to remain close to each other. It also alludes to the past of Europe, to the wars that Europe went through. Following these wars, democracy prevailed thanks to the fact that European countries were united and allies. It shows that despite Brexit, it is necessary that the countries stay united and this is the message Theresa May wishes to convey through the use of this metaphor. On the same note, calling back to the past, especially to such dramatic events can be a way to arouse emotions such as fear. Flusberg pointed out that the feeling of fear produced by the WAR metaphor can exemplify people's perception of the threat posed by an issue (2018: 13). So when politicians use the WAR metaphor to convey a negative image of Brexit, it 
exemplifies the potential threat that Brexit represents for the economy and for employment. Besides, the fact that it arouses emotions means that it also invokes pathos, which as we saw in the preceding part, is an effective rhetorical instrument to persuade an audience.

\subsubsection{EUROPE IS A GROUP OF FRIENDS}

Following this analysis, conceiving Europe as a group of friends seems to be quite recurrent in political speeches in general, and it is also the case for speeches and political communications tackling the issue of Brexit as seen in the corpus analysis. More specifically, politicians used this metaphor to refer to the relationship that unites the United Kingdom and the European Union. The FRIENDSHIP metaphor is closely related to the NATION IS A PERSON metaphor as countries are treated as people. Chilton and Lakoff considered that conceiving a nation as a person gives the impression that it can enter into social relationships with other nations, which are usually seen as enemies, neighbours, clients or even pariah (1995: 39).

As mentioned by Rémi Digonnet in his study of metaphors in American inaugural speeches, as opposed to WAR metaphors, FRIENDSHIP metaphors tend to express solidarity and will to peace (2014: 11). In the case of Brexit, the term friends is recurrent in many occurrences of the corpus. For instance, in the following sentence: "we want to remain committed partners to our friends across the continent" appears both in the 2017 Conservative Manifesto and Theresa May's letter to Donald Tusk. Interestingly enough, just as the term allies previously studied, Theresa May pronounced the word friend to refer to European countries no fewer than ten times in her speech at Lancaster House. It is a way to insist upon the 
kind of relationship she wants to maintain with the continent. Yet, friendship also involves emotions, which once again illustrate the theory raised in Part II: metaphor is an effective means of communication since it arouses emotions. Lakoff and Johnson stated that these phenomena tend to be defined in terms of human actions so that people are able to understand it "on the basis of our own motivations, goals, actions and characteristics" (1980: 34).

\section{Conclusion}

To sum up this corpus-analysis, we can come to the conclusion that both visual and verbal metaphors are omnipresent in talks surrounding Brexit, probably due to the abstractness of this concept. Consequently, Brexit is conceptualised in various ways depending on how politicians talk about it and conceptualise it. According to the results obtained from this analysis, in the visual data, Brexit seems to be mainly described as a divorce or as a sharp object whereas in verbal data, Brexit seems to be mainly portrayed as a journey, a war or impairment in the EU-UK friendship. However, the type of metaphors used and the image rendered by it depend on various factors such as whether the utterer's opinion on Europe is positive or not. 


\section{General Conclusion}

This investigation of visual and verbal metaphors in the context of Brexit had two main goals. The first one was to identify the conceptual metaphors that were used to depict Brexit in the elements of my corpus, which have been chosen carefully so as to get a global representation of the many opinions across the United Kingdom and the European Union. The second goal was to look at the images reflected of Brexit through the use of these metaphors, and see whether the images conveyed were more or less the same for each and every element of my corpus.

This study revealed that metaphors are omnipresent in political discourse and that they often go unnoticed. This is probably due to the fact they are ingrained in our conceptual system. Hence, they are processed almost instinctively by our brain. This confirms the claim of the Conceptual Metaphor Theory which consists in assuming that metaphors are pervasive in our everyday life and language.

The two main types of functions endorsed by metaphors in political discourse are the cognitive and the persuasive functions. The cognitive function is almost always performed whenever a metaphor is used, even sneakily as metaphors almost always give a sense of concreteness to abstraction. As shown in this study, even though it is not their first target, by using metaphors to depict Brexit, politicians give a more concrete sense to this event. The use of Brexit metaphors allows people to talk about it, think about it, and understand it. Besides, it is also worth mentioning that if metaphors are so recurrent in the domain of politics, it is probably not a mere coincidence. It seems that politicians use them on purpose so as to achieve their main goal, that is, persuade. They intend to persuade us, persuade their opponents, and persuade their associates. Metaphors are then used for 
rhetorical purposes, as they work as wires that connect what is unknown to what is familiar or what is part of our domain of experience. One of the most important features of metaphors in political discourse is the fact that depending on which source domain the metaphor is built upon; the connotation ascribed to it may vary. As a consequence, politicians can depict issues and their ideologies more or less positively. This was the case for the Brexit metaphors retrieved in my corpus. From what we have seen so far, it seems that the depiction of Brexit is twofold. On the one hand, Brexit is described by a majority of people in terms of a friendship. The recurrence of metaphors belonging to the same conceptual domain builds a sort of scenario where everything related to Brexit has a role and is metaphorised in the same way. The European Union and the United Kingdom are, then, pictured as friends; thus they are personified. The FRIENDSHIP metaphor scenario is rather neutral. Contrastively, this study also shows that members of anti-European parties such as Boris Johnson and Nigel Farage tended to use metaphors with a derogatory connotation to depict the European Union and positively connoted metaphors to depict Brexit. The opposite applies to those who fought against Brexit. This leads us to believe that Brexit metaphors vary depending on the political stance of the utterer, so they are thoroughly meaningful and entirely part of the persuasion process. As for a potential diatopic difference in the use of metaphors, it seems that it is connected with the difference in political stances. As we know, in Europe, people tend to disagree with Brexit, so they are more likely to use derogatory metaphors for Brexit. On the contrary, in Britain, where the Government is predominantly in favour of Brexit, they inevitably use more positive metaphors.

Furthermore, the study of visual metaphors also illustrates the fact that metaphors are ubiquitous and are not exclusively linguistic phenomena. They can 
occur in other modes through which we can also express our thoughts. The visual mode is one of them. The visual metaphors examined in this thesis are often combined with verbal elements, and sometimes, the verbal elements match the visual elements, as it is the case with the BOAT metaphor.

To some extent, this study shows that language can, indeed, be perceived as a tool that shapes our consciousness and unconsciousness. The words we use to talk about an issue shape the way we conceive this issue. This is due to the connotation that words carry. This happens to be true too for Brexit. It seems that the metaphors used to talk about it gives concreteness to this event and shape the way we perceive it. 


\section{Bibliography}

\section{PRIMARY SOURCES}

VISUAL DATA (All accessed 19 May 2018)

CBIES, "UK and EU Road Sign Against Blue Sky" [Digital Image], Thinkstock, http://www.thinkstockphotos.fr/image/photo-brexit-uk-and-eu-road-sign-againstsky-3d/616238172/popup?sq=brexit/f=CPIHV/p=16/s=DynamicRank.

CHANU, "If this continues, we're setting sails!" [Cartoon], Ouest France, 23 January 2013, http://beyond.blogs.france24.com/article/2013/01/24/david-cameron-franceeuropean-union-referendum-uk-exit-eu-0.html.

GARRISON Ben, “Abandon Ship” [Cartoon], Twitter, 24 June 2016, https://twitter.com/GrrrGraphics/status/746331297480507393/photo/1.

McHUGH Jonathan, "What a British Divorce from the EU Would Look Like" [Digital Image], Financial Times, 28 June 2016, https://www.ft.com/content/7e0bce28-dbda-11e5a72f-1e7744c66818.

“UK vs EU, Amicable Divorce?" [Digital Image], eunotforme.com, http://eunotforme.com/index.php/245-uk-vs-eu-amicable-divorce.

VERBAL DATA (All accessed 19 May 2018)

CAMERON David, EU Speech at Bloomberg, Bloomsberg Institute, 23 January 2017 [Transcript]. Available at: https://www.gov.uk/government/speeches/eu-speechat-bloomberg.

CONSERVATIVE PARTY, The Conservative Party Manifesto 2017. Available at: http://www.conservatives.com/Manifesto.

CONSERVATIVE PARTY, The Conservative Party Manifesto 2015. Available at: https://www.conservatives.com/manifesto2015.

European Parliament, Plenary Session, Negotiations with the United Kingdom Following its Notification that it Intends to Withdraw from the EU, 5 April 2017 [Transcript]. Available at: http://www.europarl.europa.eu/sides/getDoc.do?type=CRE\&reference=20170405 \&secondRef $=$ ITEM-006\&language $=\mathrm{EN}$ 
JOHNSON Boris, EU Referendum Vote Leave Speech, David Nieper Factory, 16 May 2016. Available at: https://www.youtube.com/watch?v=hcWzwK2CRhA.

MAY Theresa, Speech by Theresa May, Lancaster House, 17 January 2017 [Transcript]. Available at: https://www.independent.ie/business/brexit/theresa-mays-brexitspeech-in-full-35374214.html.

MAY Theresa, "Prime Minister's Letter to Donald Tusk Triggering Article 50." Received by Donald Tusk, 29 March 2017, London. Available at: https://www.gov.uk/government/publications/prime-ministers-letter-to-donaldtusk-triggering-article-50

STURGEON Nicola, Nicola Sturgeon Speech on Brexit, David Hume Institute, 17 January 2018 [Transcript]. https://www.snp.org/nicola_sturgeon_speech_on_brexit_at_the_david_hume_institu te.

\section{SECONDARY SOURCES}

\section{BOOKS}

CHARTERIS-BLACK Jonathan, Politicians and Rhetoric: The Persuasive Power of Metaphors. Hampshire, New York: Palgrave Macmillan, 2006.

CHARTERIS-BLACK Jonathan, Corpus Approaches to Critical Metaphor Analysis. Hampshire, New York: Palgrave Macmillan, 2004.

CHILTON Paul, Analysing Political Discourse: Theory and Practice. Oxon: Routledge, 2004.

DEIGNAN Alice, Metaphor and Corpus Linguistics. Amsterdam, Philadelphia: John Benjamins Publishing, 2005.

ECO Umberto, La Guerre du Faux. Paris: Editions Grasset, 1985.

ERICKSON V. Keith, Aristotle's Rhetoric: Five Years of Philological Research. Metuchen: Scarecrow, 1975.

FAUCONNIER Gilles, TURNER Mark, The Way We Think: Conceptual Blending and the Mind's Hidden Complexities. New York: Basic Books, 2002.

FORCEVILLE Charles, Pictorial Metaphor in Advertising. London: Routledge, 1996.

FORCEVILLE Charles, URIOS-APARISI Eduardo, Multimodal Metaphor. Berlin: Mouton de Gruyter, 2009. 
GIBBS W. Raymond, STEEN J. Gerard, Metaphor in Cognitive Linguistics. Amsterdam: John Benjamins Publishing, 1999.

GOATLY Andrew, The Language of Metaphors, London and New York: Routledge, 1997.

HAGUE Rod, HARROP Martin, Comparative Government and Politics: An Introduction. London: Palgrave Macmillan, 1998.

HALMARI Helena, VIRTANEN Tuija, Persuasion Across Genres: A Linguistic Approach. Amsterdam: John Benjamins Publishing, 2005.

KNOWLES Murray and MOON Rosamund, Introducing Metaphor. London: Routledge, 2006.

KÖVECSES Zoltán, Language, Mind and Culture: A Practical Introduction. Oxford: Oxford University Press, 2006.

LAKOFF George, TURNER Mark, More than Cool Reason. A Field Guide to Poetic Metaphor. Chicago: The University of Chicago Press, 1989.

LOCKE John, An Essay Concerning Human Understanding. Oxford, New York: Clarendon Press, 1950.

MITCHELL Peta, Contagious Metaphor. London: Bloomsbury, 2012.

MÜLLER Cornelia, Metaphors Dead and Alive, Sleeping and Walking: A Dynamic View. Chicago: The University of Chicago Press, 2008.

NIETZSCHE Friedrich, Le Livre du Philosophe. Etudes Théorétiques. Paris: Garnier Flammarion, 1991.

ORWELL George, Politics and the English Language. London: Penguin Books, 1946.

PIKALO Jernej and CARVER Terrell, Political Language and Metaphor: Interpreting and Changing the World. Abingdon: Routledge, 2008.

RICHARDS I.A., The Philosophy of Rhetoric. Oxford: Oxford University Press, 1981.

RICOEUR Paul, La Metaphore Vive. Paris: Edition du Seuil, 1975.

SEMINO Elena, Metaphor in Discourse. Cambridge: Cambridge University Press, 2008.

SHIELDS Christopher, The Oxford Handbook of Aristotle. Oxford: Oxford University Press, 2012.

STERN Joseph, Metaphor in Context. Cambridge, London: Massachusetts Institute of Technology Press, 2000.

VAN DIJK Teun A., Discourse and Power. New York: Palgrave Macmillan, 2008. 


\section{ARTICLES}

ALEXANDRE-COLLIER Agnes, "Euroscepticism Under Margaret Thatcher and David Cameron: From Theory to Practice" in Observatoire de la Société Britannique, 17, 2015: 115-133.

BARTHES Rolland, "Rhétorique de l'Image” in Communication, 4, 1964: 40-51.

BOUGHER Lori D., "The Case of Metaphor in Political Reasoning and Cognition" in Political Psychology, 33, 2012: 145-163.

CACCIARI Cristina, "Why Do We Speak Metaphorically? Reflections on the Functions of Metaphor in Discourse and Reasoning", in Katz Albert N., Cacciari Cristina, Gibbs Raymond W. and Turner Mark (eds.) Figurative Language and Thought, New York and Oxford, Oxford University Press, 1998: 119-157.

CAMMAERTS Bart "The Strategic Use of Metaphors by Political and Media Elites: the 200711 Belgian Constitutional Crisis" in International Journal of Media and Cultural Politics, 2012: 229-249.

CHILTON Paul, ILYIN Mikhail, "Metaphor in Political Discourse: The Case of the Common European House" in Discourse and Society, 4(1), 1993: 7-31.

CHILTON Paul, LAKOFF George, "Foreign Policy by Metaphor" in C. Schaffner and A. Wenden (eds.) Language and Peace, Aldershot: Ashgate, 1995: 37-60.

DE LANDTSHEER Christel, "Crisis Style or Radical Rhetoric? The Speech by Dyab Abou Jahjah Leader of the Arab European League" in Critical Discourse Analysis: Application and Theory, Newcastle: Cambridge Scholar Publishing, 2007: 57-80.

DIGONNET Rémi, "Power and Metaphor: Towards More Executive Power in American Presidents' Inaugural Addresses?" in Lexis (online), 8, 2014. Available at: https://journals.openedition.org/lexis/224.

DIRVEN René, "Metaphor and Ideology" in Revue Belge de Philologie et d'Histoire, 1990: 565575.

DUNMIRE Patricia, "Political Discourse Analysis: Exploring the Language of Politics and the Politics of Language" in Language and Linguistic, 6, 2012: 735-751.

DUROVIC Tatiana, SILASKI Nadezda, "The End of a Long and Fraught Marriage: Metaphorical Images Structuring the Brexit Discourse" in Metaphor and the Social World, 8(1), 2018 (forthcoming). Available at: https://www.researchgate.net/publication/317955792_The_end_of_a_long_and_fra ught_marriage_Metaphorical_images_structuring_the_Brexit_discourse.

FAUCONNIER Gilles, TURNER Mark, "Blending as a Central Process of Grammar" in Adele Goldberg (ed.) Conceptual Structure, Discourse and Language, 1998: 113-130.

FLUSBERG J. Stephen, MATLOCK Teenie, THIBODEAU H. Paul, "War Metaphors in Public Discourse" in Metaphor and Symbol, 33(1). 2018: 1-18. 
FORCEVILLE Charles, "Pictorial and Multimodal Metaphor" in The Language in Multimodal Contexts Handbook. Berlin: Mouton de Gruyter, 2016.

FORCEVILLE Charles, "The Identification of Target and Source in Pictorial Metaphors" in Journal of Pragmatics, 34(1), 2002: 1-14.

GENTNER Dedre, BOWDLE Brian, "Metaphor as Structure-Mapping" in Gibbs W. Raymond (ed.) The Cambridge Handbook of Metaphor and Thought. Cambridge: Cambridge University Press, 2008: 109-128.

GIBBS W. Raymond, "Taking Metaphor out of our Heads and Putting it into the Cultural Metaphorical Images" in Gibbs W. Raymond and Steen Gerard Metaphor in Cognitive Linguistics. Amsterdam: John Benjamin Publishing, 1999: 145-166.

GLUCKSBERG Sam, "How Metaphors Create Categories - Quickly" in Gibbs Raymond W. (ed.) The Cambridge of Metaphor and Thought. Cambridge: Cambridge University Press, 2008: 67-83.

GRADY Joseph, "A Typology of Motivation for Conceptual Metaphor: Correlation vs Resemblance" in Gibbs W. Raymond and Steen Gerard (eds.) Metaphor in Cognitive Linguistics. Amsterdam: John Benjamin Publishing, 1999: 79-100.

HART Christopher, "Critical Discourse Analysis and Metaphor: Toward a Theoretical Framework" in Critical Discourse Studies, 5(2), 2008: 91-106.

HALL J. Douglas, "Bulldog Churchill: The Evolution of a Famous Image" in Finest Hour, 106, 2000: 18-20.

JOHNSON J. Eric, "Sculpting Public Opinion: Understanding the (mis)use of Metaphors in the Media" in Critical Discourse Analysis: Application and Theory, Newcastle: Cambridge Scholar Publishing, 2007: 28-54.

KHEOVICHAI Baramee, "Metaphorical Scenarios in Business Science Discourse" in Iberica, 29, 2015: 155-178.

KOLLER Veronika, "Brand Images: Mulitmodal Metaphor in Corporate Branding Messages" in Forceville Charles and Urios-Aparisi (eds.) Multimodal Metaphor, 2009: 42-67.

LAKOFF George, "The Contemporary Theory of Metaphor" in Andrew Ortony (ed.) Metaphor and Thought, Cambridge: Cambridge University Press, 1993: 205- 251.

LANDALE James, "Brexit Means What? Time for the Metaphors to Stop." BBC, 2017. Retrieved from http://www.bbc.com/news/uk-politics-40726215. [Last accessed 28th April 2018.]

LI Wei, "Rethinking Critical Metaphor Analysis" in International Journal of English Linguistics, 6(2), 2016: 92-98.

LOUW Bill, " Irony in the Text or Insincerity in the Writer? The Diagnostic Potential of Semantic Prosodies" in Baker M., Francis G. Tognini-Bonelli (eds.) Text and Technology: In Honour of John Sinclair. Philadelphia, Amsterdam: John Benjamins Publishing, 1993: 157-76. 
MAX Black, "More About Metaphor" in Ortony Andrew (ed.) Metaphor and Thought. Cambridge: Cambridge University Press, 1993: 19-41.

MOROZOVA Olena, "Monomodal and Multimodal Instantiations of Conceptual Metaphors of Brexit" in Lege Artis. Language yesterday, today tomorrow. Warsaw: De Gruyter. 2017: 250-283.

MULLER Cornelia and CIENKI Alan, "Words, Gestures and Beyond: Forms and Multimodal Metaphors in the Use of Spoken Language" in Forceville Charles and Eduardo Urios-Aparisi (eds.) Multimodal Metaphor, 2009: 298-320.

MUSOLFF Andreas, "Metaphor Scenarios in Public Discourse" in Metaphor and Symbol, 21(1). New Jersey: Lawrence Erlbaum Associates, 2006: 23-38.

MUSOLFF Andreas, "Political Imagery of Europe: A House without Exit Doors?" in Journal of Multilingual and Multicultural Development, 21(3). 2000, 216-229.

MUSOLFF Andreas, "How Metaphors Can Shape Political Reality: The Figurative Scenarios at the Heart of Brexit" in Language and Communication Studies, 2017: 2-16.

MUSOLFF Andreas, "The Study of Metaphor as Part of Critical Discourse Analysis" in Critical Discourse Studies, 9(3), 2012: 301-310.

MUSOLFF Andreas, "Is There Such a Thing as Discourse History? The Case of Metaphor" in Hart Christopher and Lukes Dominik (eds.) Critical Discourse Analysis: Application and Theory, Newcastle: Cambridge Scholar Publishing, 2007: 1-27.

NEGRO Isabel, "Pictorial and Verbo-Pictorial Metaphor in Spanish Political Cartooning" in Círculo de lingüística Aplicada a la Comunicación, 57, 2015: 59-84.

OSWALD Steve, RIHS Alain, "Metaphor as Argument: Rhetorical and Epistemic Advantages of Extended Metaphors" in Argumentation, 28(2), 2014: 133-159.

PYLIACHYK N. Ye, VASYLYK O., "The 'EU' and 'Brexit' Concepts in the British Political Discourse: Cognitive Approach in Journal of Vasyl, Stefanyk Precarpathian National University, 3(4), 2016: 27-32.

REYES Antonio, "Building Intimacy Through Linguistic Choices, Text Structure and Voices in Political Discourse" in Language and Communication, 43, 2015: 58-71.

RIGOTTI Francesca, "La Théorie Politique et ses Metaphores" in Revue Belge de Philologie et d'Histoire, 68(3), 1990: 548-564.

STEEN Gerard, "From Linguistic to Conceptual Metaphor in Five Steps" in Gibbs W. Raymond and Steen Gerard (eds.) Metaphor and Cognitive Linguistics. Amsterdam: John Benjamin Publishing, 1999: 57-77.

STEEN Gerard, "Identifying Metaphor in Language: A Cognitive Approach" in Cognitive Approach to Figurative Language, 2002: 386-406.

THOMPSON Sandra, "Politics Without Metaphors is Like a Fish Without Water" in Metaphor: Implications and Applications. New Jersey: Lawrence Erlbaum Associates, 1996: 185-202. 
WAGNER Franc, "Cultural Aspects of Metaphor Scenarios" in The Polish Journal of Arts and Culture, 2016: 73-88.

WEE Lionel, "Constructing the Source: Metaphor as a Discourse Strategy" in Discourse Studies, 2005: 363-384.

YUS Fransisco, "Metaphor vs Verbal Metaphor" in Forceville Charles and Eduardo UriosAparisi (eds.) Multimodal Metaphor, 2009: 153-168.

\section{THESIS}

LESZ Barbara, To Shape the World for the Better: An Analysis of Metaphors in the Speeches of Barack Obama (Master's thesis), 2011. Retrieved from https://munin.uit.no/bitstream/handle/10037/3540/thesis.pdf?sequence=\&is. [Last accessed 26 March 2018.]

VERSTERMARK Ida, "Metaphors in Politics: A study of the Metaphorical Personification of America in Political Discourse" (Dissertation), 2007. Available at: http://urn.kb.se/resolve?urn=urn:nbn:se:ltu:diva-48119. [Last accessed 26 March 2018.]

\section{INTERVIEW}

MARTÍ Dominguez, Interview with Charles Forceville in Mètode, 96, 2018: 4-9.

\section{BLOG POST}

WILDING Peter, "Stumbling Towards the Brexit." BlogActiv, 12 May 2012, Available at: blogactiv.eu/blog/2012/05/15/stumbling-towards-the-brexit/. [Last accessed 22 March 2018.]

\section{LECTURE}

FORCEVILLE Charles, A Course on Pictorial and Multimodal Metaphor, 2010. Available at: http://projects.chass.utoronto.ca/semiotics/cyber/cforceville6.pdf. [Last accessed 19 February.] 